\title{
Naturally Derived Heme-Oxygenase 1 Inducers and Their Therapeutic Application to Immune-Mediated Diseases
}

\author{
Samanta C. Funes ${ }^{1}$, Mariana Rios ${ }^{1}$, Ayleen Fernández-Fierro ${ }^{1}$, Camila Covián ${ }^{1}$, \\ Susan M. Bueno', Claudia A. Riedel ${ }^{2}$, Juan Pablo Mackern-Oberti ${ }^{3,4}$ and \\ Alexis M. Kalergis ${ }^{1,5 *}$ \\ ${ }^{1}$ Departamento de Genética Molecular y Microbiología, Millenium Institute on Immunology and Immunotherapy, Facultad de \\ Ciencias Biológicas, Pontificia Universidad Católica de Chile, Santiago, Chile, ${ }^{2}$ Departamento de Ciencias Biológicas, \\ Millenium Institute on Immunolgy and Immunotherapy, Facultad Ciencias de la Vida, Universidad Andrés Bello, Santiago, \\ Chile, ${ }^{3}$ Instituto de Medicina y Biología Experimental de Cuyo, IMBECU CCT Mendoza- CONICET, Mendoza, Argentina, \\ ${ }^{4}$ Facultad de Ciencias Médicas, Instituto de Fisiología, Universidad Nacional de Cuyo, Mendoza, Argentina, ${ }^{5}$ Departamento \\ de Endocrinología, Facultad de Medicina, Pontificia Universidad Católica de Chile, Santiago, Chile
}

OPEN ACCESS

Edited by:

Kutty Selva Nandakumar

Southern Medical University, China

Reviewed by:

Miri Blank,

Sheba Medical Center, Israel Anna Villa,

National Research Council (CNR), Italy

*Correspondence:

Alexis M. Kalergis

akalergis@bio.puc.cl

Specialty section:

This article was submitted to Autoimmune and Autoinflammatory

Disorders,

a section of the journa

Frontiers in Immunology

Received: 16 March 2020

Accepted: 05 June 2020

Published: 23 July 2020

Citation:

Funes SC, Rios $M$,

Fernández-Fierro A, Covián $C$

Bueno SM, Riedel CA,

Mackern-Oberti JP and Kalergis AM

(2020) Naturally Derived

Heme-Oxygenase 1 Inducers and

Their Therapeutic Application to

Immune-Mediated Diseases.

Front. Immunol. 11:1467.

doi: 10.3389/fimmu.2020.01467
Heme oxygenase $(\mathrm{HO})$ is the primary antioxidant enzyme involved in heme group degradation. A variety of stimuli triggers the expression of the inducible $\mathrm{HO}-1$ isoform, which is modulated by its substrate and cellular stressors. A major anti-inflammatory role has been assigned to the $\mathrm{HO}-1$ activity. Therefore, in recent years $\mathrm{HO}-1$ induction has been employed as an approach to treating several disorders displaying some immune alterations components, such as exacerbated inflammation or self-reactivity. Many natural compounds have shown to be effective inductors of $\mathrm{HO}-1$ without cytotoxic effects; among them, most are chemicals present in plants used as food, flavoring, and medicine. Here we discuss some naturally derived compounds involved in $\mathrm{HO}-1$ induction, their impact in the immune response modulation, and the beneficial effect in diverse autoimmune disorders. We conclude that the use of some compounds from natural sources able to induce $\mathrm{HO}-1$ is an attractive lifestyle toward promoting human health. This review opens a new outlook on the investigation of naturally derived $\mathrm{HO}-1$ inducers, mainly concerning autoimmunity.

Keywords: heme oxygenase 1, HO-1, autoimmunity, naturally derived compounds, inflammation

\section{INTRODUCTION}

Heme oxygenase (HO, EC 1.14.99.3) is a microsomal enzyme first described in 1968 (1) with a primary antioxidant and anti-inflammatory role involved in heme group degradation yielding carbon monoxide (CO), biliverdin, and free iron (2). To date, three HO isoenzymes (HO-1, HO2 , and HO-3) have been reported in mammals. Of these three isoenzymes, only HO-1 has been demonstrated to be inducible in response to a variety of stimuli $(3,4)$. The beneficial effect of HO-1 induction in inflammation has been associated not only with the degradation of the heme group but also with its anti-inflammatory products, biliverdin, and $\mathrm{CO}(5,6)$.

Importantly, $\mathrm{HO}-1$ induction is triggered by its substrate heme and by biological, chemical, and physiological stress conditions caused by toxic concentrations of drugs or metals (7). Therefore, 
HO-1 induction is actively involved in the oxidative response, and its induction has been used as an approach for the treatment of inflammatory diseases (8-11).

Many natural compounds have shown an effective induction of HO-1 without cytotoxic effects. Most of them are chemicals present in plants used as food, spices, flavoring, and medicine (7). In this review article, we will discuss some naturally derived compounds known to up-regulate the expression of $\mathrm{HO}-1$, the molecular mechanisms involved in HO-1 induction, and the beneficial effects of these natural compounds in different autoimmune disorders.

\section{MOLECULAR MECHANISM OF HO-1 INDUCTION}

Heme oxygenase 1 has great therapeutic potential value given that in several conditions and diseases, there are stress factors that induce the expression of HO-1 activity, reducing the inflammation. Therefore, it seems essential to better know the molecular mechanisms involved in the induction of the HO-1 expression and the regulation of its activity. In this section, we discuss the role of transcription factors and upstream signaling molecules in the modulation of HO-1 expression.

\section{Transcription Factors}

The HO-1 gene $(h m o x 1)$ is often activated under a wide range of stressful conditions. The transcriptional control of hmoxl is determined by inducible regulatory elements localized in the $5^{\prime}$ region of the promoter $(4,12)$. Distal enhancers regions identifying upstream $h \operatorname{mox} 1(13,14)$ are critical in HO-1 induction by different stimuli and contain several stressresponsive elements with binding sites for regulatory proteins $(15,16)$. Several redox-sensitive transcription factors bind to these elements, and some of them will be discussed below.

\section{Nuclear Factor-Erythroid 2-Related Factor 2}

Nuclear factor-erythroid 2-related factor 2 (Nrf2) is a transcription factor that regulates the expression of proteins functionally related to detoxification, reduction of oxidized

\footnotetext{
Abbreviations: HO-1, Heme oxygenase 1; CO, Carbon monoxide; StRE, Stressresponsive elements; DCs, Dendritic cells; NFкB, Nuclear factor $\kappa \mathrm{B}$; NF-E2, Nuclear factor-erythroid 2; Nrf2, NF-E2-related factor 2; AP-1/2, Activador protein 1/2 families; ARE, Antioxidant response element; Keap1, Kelch-like ECH-associated protein 1; MAPKs, Mitogen-activated protein kinases; PKA, Protein kinase A; PKC, Protein kinase C; PI3K, Phosphatidylinositol 3-kinase; EGCG, Epigallocatechin gallate; ROS, Reactive oxygen species; SLE, Systemic lupus erythematosus; RA, Rheumatoid arthritis; CAPE, Caffeic acid phenethyl ester; DADS, Diallyl disulfide; DATS, Diallyl trisulfide; NQO1, NAD(P)Hquinone oxidoreductase; CIA, Collagen-induced arthritis; ITC, Isothiocyanate; SFN, Sulforaphane; ERK, Extracellular regulated kinases; JNK, c-Jun N-terminal kinases; HDAC2, Histone deacetylase-2; CA, Carnosic acid; T1D, Type 1 diabetes; NOD, Non-obese diabetic; STZ, Streptozotocin; CoPP, Cobalt (III) protoporphyrin IX; IBD, Inflammatory bowel disease; CD, Crohn's disease; UC, Ulcerative colitis; DSS, Dextran sulfate sodium; MARE, Maf recognition elements; LPS, Lipopolysaccharide; cAMP, Cyclic adenosine monophosphate; cGMP, Cyclic guanidine monophosphate; IRF-3, Interferon regulatory factor-3; C3G, Cyanidin3-glucoside; ZnPP, Zinc protoporphyrin; MPP+, 1-methyl-4-phenyl pyridine ion; EAE, Experimental autoimmune encephalomyelitis; CNS, Central nervous system; MS, Multiple sclerosis; DMF, Dimethylfumarate; tolDC, Tolerogenic dendritic cell.
}

proteins, and the elimination of end products derived from reactive oxygen species (ROS) (17). Nuclear factor-erythroid 2-related factor 2 binds to small Maf protein forming a heterodimer, and then this dimer can bind to the antioxidant response element (ARE) or Maf recognition elements (MAREs) (18). These sequences are present at the HO-1 promoter; thus, the Nrf2-Maf dimer binding induces the transcriptional expression of HO-1 mRNA (19).

The activity of Nrf2 is normally repressed by the repressor Kelch-like ECH-associated protein 1 (Keap1), which sequestrate Nrf2 in the cytoplasm (20). Some electrophilic agents and ROS alter the interaction of Nrf2-Keap1 and liberate Nrf2 activity from repression (21). Moreover, Bach1, another transcriptional repressor, competes for binding, and forming heterodimers with small Maf proteins. These dimers bind to MAREs at the DNA repressing HO-1 transcription (22). However, an inductor such as heme binds to four cysteine-proline motifs in the C-terminal region of Bach and inhibits the DNA-binding activity of Bach1Maf heterodimers resulting in HO-1 induction (23).

\section{Activator Protein 1}

The activator protein 1 (AP-1) transcription factor is a dimer of Jun and Fos family proteins (24). Activator protein 1 is involved in the induction of immune responses in a great diversity of ways, including different tissues and immune or non-immune cell types $(25,26)$. Interestingly enough, AP-1 homodimers or heterodimers bind to enhancers flanking the promoter region of hmox1 (14). The induction of HO-1 expression requires AP-1 activation to respond to some oxidative inducers $(27,28)$, such as lipopolysaccharide (LPS) (29).

\section{Upstream Signaling Molecules}

The activation of the transcription factors mentioned above can be indirectly modulated by various proteins with (de)phosphorylation or reduction-oxidation activity, such as the mitogen-activated protein kinases (MAPKs), phosphatidylinositol 3-kinase (PI3K), and other protein kinases, leading to HO-1 regulation. These signaling pathways and their association to the immune response will be described below.

\section{Mitogen-Activated Protein Kinases}

The activation of MAPKs has been suggested to play a critical role in HO-1 up-regulation (4). Among them, three major subfamilies of MAPKs have been described in HO-1 expression modulation: the extracellular regulated kinases (ERK), c-Jun $\mathrm{N}$-terminal kinases (JNK), or stress-activated kinases, and p38 $(4,30)$. Thus, p38 function has been involved in the HO1 induction by isoproterenol (31), ethanol extract of Inula helenium (32), and tetrahydroisoquinoline alkaloid THI-28 (33) in RAW 264.7 macrophages. In addition, khayandirobilide A, an anti-inflammatory compound from Khaya senegalensis, induces HO-1 expression by $\mathrm{p} 38 \mathrm{MAPK} / \mathrm{Nrf2}$ signaling in RAW 264.7 macrophages and BV-2 microglial cells (34). Besides, p38 inhibition has been reported to induce HO-1 expression mediated by Nrf2 in monocytes, (35) human leukocytes (36), and RAW 264.7 macrophages (37). 
On the other hand, the induction of HO-1 expression by cadmium has been reported to be JNK and ERK pathwaymediated in the lymphocyte B-cell line BJAB cells in a dose-dependent manner (38). Moreover, inhibition of the JNK pathway is involved in the anti-inflammatory effects of kalopanaxsaponin A from Kalopanax pictus (39) and sulforaphane (SFN) (40) in LPS-stimulated microglia. Also, ethanol-treated rat Kupffer cells display increased mRNA expression of $\mathrm{HO}-1$ mediated by $\mathrm{Nrf} 2$, hypoxia-inducible factor $1 \alpha$, and JNK-1 (41). Moreover, HO- 1 is induced in microglia by the activation of $\mathrm{Nrf} 2$ via the ERK signaling pathway under astragaloside IV (42) and artesunate treatment (43). Accordingly, the MAPK pathway involved HO-1 up-regulation, which probably is dependent on the cell type and inducer. Hence, more studies should be performed to improve the understanding of the mechanisms underlying the regulation of $\mathrm{HO}-1$ expression.

\section{Phosphatidylinositol 3-Kinase}

In diverse models, it has been shown that HO-1 expression could be up-regulated via PI3K/Akt pathway and Nfr2 $(44,45)$. Most of the studies report the induction of HO-1-mediated via PI3K in immune cells described in cells from the innate system. Heme oxygenase 1 induction has also been reported to be PI3k mediated in RAW 264.7 macrophages after isoproterenol treatment (31). The anti-inflammatory effects of schisandrin from Schisandra chinensis in LPS-stimulated RAW 264.7 have been due to the induction of HO-1 expression through Nrf-2 and PI3K/Akt activation. Interestingly, the down-regulation of the PI3K/Akt signaling pathway increases $\mathrm{Nrf} 2 / \mathrm{HO}-1$ and inhibits mast cell degranulation (46). Besides, edaravone (a radical scavenging agent) reduces experimental autoimmune thyroiditis severity in a PI3K/Akt pathway-dependent way by inducing HO-1 (47).

\section{Others Protein Kinases}

Heme oxygenase 1 expression can involve different upstream signaling according to the cell type evaluated, as was mentioned before. Thus, several signaling cascades have been associated with $\mathrm{HO}-1$ up-regulation, including protein kinase A (PKA), and $\mathrm{C}$ (PKC). For example, in LPS-mature dendritic cells (DCs) from a mouse model of Parkinson disease, HO-1 is regulated via AMPK (48). Also, morin (a flavonoid from fruits) down-regulates MAPK and PI3K/Akt pathways, while it induces PKA/CREB and Nrf2/HO-1 signaling in LPS-stimulated microglia (49). Besides, PKG signaling and PKC signaling show to be part of the upregulation of HO-1 expression (50). For example, $\mathrm{PKC} \alpha / \beta \mathrm{II}$ is an upstream molecule of $\mathrm{Nrf}-2$, required for $\mathrm{HO}-1$ expression after coniferaldehyde treatment in LPS-stimulated RAW 264.7 macrophages (51). Besides, as was described above, cadmium induces HO-1 expression mediated by the PKC pathway in the $\mathrm{BJAB}$ cells (38). In addition, oxidized phospholipids induce HO1 expression in human endothelial cells by the activation of $\mathrm{PKC}$, PKA, and MAPK (52), and similarly, tumor necrosis factor $\alpha$ (TNF- $\alpha$ ) and interleukin $1 \alpha$ (IL-1 $\alpha$ ) induce HO-1 expression by PKC activity (53). On the other hand, an increase in cAMP and cGMP also induces the expression of HO-1 (54). Accordingly, PKA has been studied as an upstream signal for HO-1 induction, because a large number of extracellular stimuli are capable of increasing cAMP or cGMP in the intracellular space, and this increase up-regulates $\mathrm{HO}-1$ expression (55).

\section{Epigenetic Modulation}

Gene expression can also be regulated by chromatin changes in response to environmental signals through histone modifications (56). Although the epigenetic regulation of hmoxl is poorly studied, deacetylation and phosphorylation have been observed to be involved in the modulation of its transcription (5759). Thus, the reduction in histone acetylation can inhibit the Mn-induced Nrf2 translocation to the nucleus and the HO-1 expression in nerve cells (57). Additionally, histone deacetylase 2 (HDAC2) has been reported to inhibit the $\mathrm{Nfr} 2 / \mathrm{HO}-1$ pathway in cystic fibrosis epithelial cells (58). Interestingly, the indirect involvement of histone deacetylase 6 (HDAC6) in HO1 expression has also been reported, although the epigenetic modification on $h m o x 1$ was not directly evaluated (60).

On the other hand, the environmental inorganic arsenite induces Nrf2/HO-1 expression in human hepatocytes (61). That occurs by the increase in serine 10 phosphorylation in histone $\mathrm{H} 3$ (H3S10) in the promoter region of the gene hmoxl, activating its transcription in HaCat keratinocytes (59). Thus, although there is little information about the epigenetic modulation of $\mathrm{HO}-1$, its expression also could, directly and indirectly, be regulated by epigenetic modifications.

\section{HO-1 MECHANISMS OF IMMUNE MODULATION}

The HO-1 activity has been reported to impact both innate and adaptive immune responses, contributing to resolve early inflammation and limiting subsequent tissue damage (62). The function of HO-1 in the immune system is evidenced in part by the alterations reported in knockout mice. Splenomegaly, lymphadenopathy, and changes in the number of $\mathrm{CD} 4^{+} \mathrm{T}$ cells, as well as increased immunoglobulin $\mathrm{M}$ level, are observed in hmox $1^{-/-}$mice $(62,63)$.

Immunomodulation dependent on HO-1 activity is reported in almost all the immune cells. This broad range of action could be related both to the products obtained from heme degradation reaction and the consumption of heme per se, which all have protective effects (64). Heme, a complex of iron and protoporphyrin IX is the prosthetic group of heme proteins. The activity of the HO-1 is essential in the recycling of the heme group, and this is evidenced by the anemia and iron overload observed in $h m o x 1^{-/-}$mice (65). Under pathogenic conditions, the heme group released from the hemoproteins binds to TLR4, triggering the production of proinflammatory cytokines by macrophages (66). However, HO-1 induction in these cells not only removes heme from circulation but also triggers a functional switch toward the anti-inflammatory phenotype (67). Accordingly, HO-1 up-regulation has been extensively related to M2 polarization (68). The importance of HO-1 in cells from the myeloid linage is highlighted by conditional $h m o x 1^{-/-}$mice that are prone to viral infections and inflammatory conditions (69). Accordingly, CO inhibits TLR signaling pathway (70) and 
down-regulates the TLR4 ligand HMGB1, reducing the lethality in endotoxemia models (71). Moreover, HO-1 modulates type I interferon (IFN) production in macrophages and DCs, this effect has been suggested to be mediated by direct HO-1 binding to IFN regulatory factor 3 (IRF3) (69), as well as CO effect in IRF3 signaling (72).

On the other hand, HO-1 inhibits the LPS-induced production of inducible nitric oxide synthase (iNOS), cyclooxygenase 2 (COX2), proinflammatory cytokines, and MIP-1 in macrophages by CO and MAPK signaling $(67,68,73)$. Furthermore, HO-1 induction in mast cells suppresses the degranulation and proinflammatory cytokine production (74). Interestingly, a suppressor role of $\mathrm{HO}-1$ in $\mathrm{T}$-cell priming of adaptive responses has been suggested. Thus, the pharmacological up-regulation of HO-1 in DCs induces a tolerogenic profile and the consequent regulatory $\mathrm{T}$ (Treg) cell induction $(75,76)$.

Pharmacological modulation of $\mathrm{HO}-1$ alters $\mathrm{CD}^{+}$and $\mathrm{CD} 8^{+}$ T-cell activity (77) and has been associated with $\mathrm{CO}$ and biliverdin/bilirubin reactivity (78). Regulatory T-cell activity is also modulated by $\mathrm{HO}-1$, although the reported information has been more challenging to interpret. These cells show constitutive expression of $\mathrm{HO}-1$, and its inhibition decreases in vitro Treg cell function (79); nevertheless, $h m o x 1^{-/-}$mice do not show Treg functionality alterations (80). Interestingly, HO-1 deficiency in DCs impacts Treg cell immunosuppressive effect (81), suggesting that HO-1 could be indirectly involved in Treg function impairment. On the other hand, biliverdin and bilirubin interfere in $\mathrm{CD} 4^{+} \mathrm{T}$-cell activation $(82,83)$, whereas $\mathrm{CO}$ inhibits lymphoproliferation (78). Besides, activated Treg cells induce a suppressive phenotype in neutrophils by initiating $\mathrm{HO}$ 1 expression (84). Interestingly, it has been proposed that these products of $\mathrm{HO}-1$ activity may remotely regulate $\mathrm{T}$-cell function.

Considering that the suppressing effect of $\mathrm{HO}-1$ on the immune system impacts both innate and adaptive responses, the use of inducers of this enzyme is a promising approach for autoimmune and autoinflammatory disease treatment (85). Importantly, an increasing number of reports have pointed to a regulatory effect of $\mathrm{HO}-1$ and especially to its reaction end products on immune responses. In this way, the benefit of the clinical application of these products (CO, bilirubin/biliverdin) might be an exciting approach. But an intensive study of doseffect is required because all of them possess toxic properties in higher concentrations or chronic administration (86).

\section{NATURALLY DERIVED HO-1 INDUCERS}

As mentioned previously, high amounts of heme, which is the natural inducer of HO-1, have strong cytotoxic effects triggering various inflammatory events. Thus, the subsequent induction of HO- 1 enzyme is considered a negative feedback mechanism that protects from the pathogenic effects of its inducer, maintaining homeostasis (87). Along these lines, importance of establishing the correct dose for each inductor has been underscored. In low doses, the heme group has been shown to have a beneficial antiinflammatory effect depending on the activity of HO-1 and its reaction products in immune disorders (88). However, at doses that exceed the capacity of the enzyme or in individuals with other base pathogenic conditions, the heme group could have a detrimental impact. The same concept must be applied to the use of other inductors, knowing that HO-1 expression can be induced following the stimulus of several cytotoxic agents. Among them, sodium arsenite, ultraviolet A radiation, hydrogen peroxide, and structural analogs of heme have been described (7, 44, 61, 89). Special attention must be assigned to establish the correct doses of these substances to be administered (86). This is a special issue when we evaluate compounds of natural origin, which frequently are in the form of complex mixtures, not available for absorption and in very low proportions. Hence, beyond discussing the impact of a substance on immune cell function and its therapeutic application, it is critical to consider the bioavailability of the active component.

It is essential to highlight that, although $\mathrm{HO}-1$ induction is efficient in many scenarios as an immunomodulatory agent, its efficiency is restricted by the availability of its substrate and the patient's health status, among others. Similar to what happens with heme, the beneficial effect of $\mathrm{CO}$ and bilirubin/biliverdin is observed only at low doses because they are toxic at higher concentrations. Consequently, the doses have to be adjusted, taking into account not only the possible toxicity of the inducer but also the accumulation of the enzymatic-end products.

In this context, and taking into account the detailed considerations, HO-1 inducer compounds derived from natural sources have emerged as an exciting alternative to treat inflammatory conditions. The induction mechanisms of $\mathrm{HO}-1$ to the compounds discussed in this review article are schematically summarized in Figure 1. Although the bibliography describes a wide range of pharmacological properties for these molecules, given the scope of this review article, we will only focus on the effects related to the immune system by HO-1 induction.

\section{Quercetin}

Quercetin $\left(3,5,7,3^{\prime}, 4^{\prime}\right.$-pentahydroxyflavone) is a flavonoid commonly found in fruits and vegetables, particularly on red onion and tea leaves (90). This phytochemical is considered a potent antioxidant synthesized by plants as a defense to environmental stress (91). Hence, it has been described as an anti-inflammatory molecule by scavenging free radicals (92). The protective antioxidant effect of quercetin has been associated with the activation of MAPK-Keap1-Nrf2-ARE signaling pathways (Figure 1) (93, 94). It has been shown that quercetin induces $\mathrm{HO}-1$ at transcription and translation levels in a time- and dose-dependent manner in RAW264.7 macrophages (95) and microglia (96). Importantly, HO-1 induction in macrophages promotes the polarization toward the anti-inflammatory $\mathrm{M} 2$ profile $(68,97)$. Thus, quercetin promotes a phenotype switch in macrophages, which is beneficial in some inflammatory conditions $(98,99)$. Importantly, it has been reported that quercetin attenuates murine arthritis by activating HO-1 anti-inflammatory response, modulating the $\mathrm{T}_{\mathrm{H}} 17 /$ Treg balance (100), and reducing joint inflammation (101).

Importantly, in vitro results demonstrated the presence of quercetin-related mutagenic activity, but not seen in vivo (102). 
This difference has been attributed in part to the very low bioavailability of the quercetin. On the other hand, in vitro oxidation of quercetin leads to the formation of components. In contrast, the metabolism of an orally administered dose, as well as the protective mechanisms, might render the absence of carcinogenic effects in vivo (103). Hence, several extensive and critical reviews conclude that quercetin is unlikely to cause adverse effects in the long term.

\section{Curcumin}

Curcumin (diferuloylmethane) is a polyphenol present in the root of Curcuma (Curcuma longa). It is a bioactive pigment responsible for the characteristic yellow color, which has been long used as a food additive and in traditional medicine as an anti-inflammatory compound (104). A large number of studies have identified curcumin as a potent inductor of the expression and activity of HO-1 in a dose- and time-dependent manner (12). It is well-known that the HO-1 expression induced by curcumin requires the activation of the Nrf2/ARE pathway (Figure 1) (12). Moreover, the inhibition of HDAC2 has been involved in HO-1 induction mediated by curcumin (58). The HO-1 up-regulation mediated by curcumin has been described to promote beneficial effects in several inflammatory pathologies $(105,106)$. Thus, dietary curcumin induces HO-1 mRNA and protein in DCs and impairs the differentiation of $\mathrm{T}_{\mathrm{H}} 1 / \mathrm{T}_{\mathrm{H}} 17$ cells during experimental autoimmune encephalomyelitis (EAE) (107). Accordingly, curcumin reduces neuroinflammation in BV2 microglial cells in an HO-1-dependent way (108). Besides, other studies demonstrated that curcumin could be useful to treat inflammatory diseases, by up-regulating HO-1 through PI3K/Akt signaling (109).

There are a large number of toxicological studies of curcumin performed in various experimental models and using different forms of curcumin (extracts, particles, suspensions, etc.). Although most in vivo studies do not report toxic effects (110), some in vitro studies showed mutagenic effects due to damage to mitochondrial and nuclear DNA using high doses (111). Although curcumin exhibits excellent anti-inflammatory properties, and researchers have published that there is little toxicity in vivo, their low stability, poor absorption, and rapid metabolism have promoted the development of synthetic analogs to be implemented in the clinic $(112,113)$.

\section{Carnosic Acid and Carnosol}

Carnosic acid (CA) and its oxidative product carnosol are phenolic diterpenes extracted from Lamiaceae plants such as rosemary (Rosmarinus officinalis) and common salvia (Salvia officinalis) (114). Both compounds have potent antiinflammatory and antioxidant properties $(115,116)$. The HO1 up-regulation by carnosol treatment has been reported to be mediated by PI3K/Akt/Nrf2 pathway, as is shown schematically in Figure 1 (117). Besides, CA up-regulates HO-1 expression in several cell types, such as RAW264.7 macrophages (118), and suppresses the generation of ROS and nitric oxide (NO). On the other hand, it has been shown that carnosol induces HO-1 expression in DCs, reducing its production of proinflammatory cytokines and preventing the induction of T-cell responses (119).
Furthermore, in another study, the DC maturation induced by LPS is reduced by carnosol through the up-regulation of HO-1, via activation of AMPK (120).

Interestingly, carnosol has also been described as one of the compounds with the best induction of $\mathrm{HO}-1 /$ low cytotoxicity profile in BV2 microglial cells in vitro (121). Nevertheless, a recent study has indicated that carnosol induces DNA damage, although this activity is associated with abnormal topoisomerase activity in lymphoblastoid TK6 cells (122). Importantly, these compounds have the lowest cytotoxicity when compared to other compounds such as allyl isothiocyanate (ITC) or caffeic acid phenethyl ester (CAPE) (121). Furthermore, although diterpenes are well-absorbed orally, the bioavailability can be increased by encapsulation that protects from the degradation during digestion (123).

\section{Resveratrol}

Resveratrol (3,5, $4^{\prime}$-trihydroxystilbene) is a polyphenol present in many fruits and vegetables, including grapes, cocoa, peanuts, berries, and wine (124). Among the biological properties associated with resveratrol, antioxidant, anti-inflammatory, and metabolic functions have been described (125). Cytoprotective and anti-inflammatory properties of resveratrol have been related to the inhibition of nuclear factor $\kappa \mathrm{B}(\mathrm{NF} \kappa \mathrm{B})$ signaling and PI3K/Akt pathway and HO-1 induction (126). Importantly, it has been reported that resveratrol induces $\mathrm{HO}-1$ expression by Nrf2 activation, as schematically shown in Figure 1 (126, 127). Moreover, resveratrol induces HO-1 expression by AMPK/Nrf2/ARE pathway-dependent Jurkat cells, which in part renders the cytoprotective features of resveratrol in human $\mathrm{T}$ cells (128).

On the other hand, it has been observed that some resveratrol metabolites mimic some of the beneficial effects of resveratrol. Accordingly, piceatannol also induces HO-1 expression (129) and has similar cytotoxicity in RAW 264.7 macrophages (130). Despite the mentioned benefits of resveratrol, its use has been limited because of its low bioavailability (131). Thereby, several strategies have been surged as encapsulation or conjugation in nanotechnology-based carriers tending to increase their pharmacokinetics effectiveness (132).

\section{Anthocyanins}

Anthocyanins are water-soluble pigments present in vegetables, flowers, and fruits such as berries, which confers it a bright red, blue, or purple color (133). Chemically, anthocyanins are phenolic compounds belonging to flavonoids. It is important to note that different effects have been reported using distinct anthocyanins, being cyanidin-3-glucoside (C3G), cyanidin-3xylosylrutinoside, and cyanidin-3-rutinoside those with stronger anti-inflammatory effect (134). On the other hand, the use of individual, purified compounds exhibits a weaker effect than those observed using a mixture of both (135). On the other hand, some reports have found that antioxidant and anti-inflammatory effects of anthocyanins are associated with the Nfr2-mediated HO-1 induction (Figure 1) (136138). Importantly, anthocyanins orally administered ameliorate 
inflammatory arthritis in the CIA murine model by decreasing the $\mathrm{T}_{\mathrm{H}} 17$ cell number and suppressing $\mathrm{NF} \kappa \mathrm{B}$ signaling (139).

Similarly, concentrated C3G-blue honeysuckle extract administration attenuates rat arthritis symptoms and enhances Nrf2/HO-1 expression and reduces iNOS and COX2 in RAW264.7 cells (140). Moreover, anthocyanins induce expression of Nrf2/HO-1 and modulate T-cell function (141). Importantly, it has been observed that C3G has proapoptotic and antiproliferative effects at concentrations found in human blood. Although a toxic in vivo effect remains to be demonstrated, diet consumption appears to be safe; it is essential to evaluate high doses and combined treatments (142). Importantly, anthocyanins can be absorbed all along gastrointestinal tract and metabolized by the microbiota (143). Thus, the bioavailability of anthocyanins has been suggested to be underestimated by the methods used or by not considering their metabolites (144).

\section{Epigallocatechin Gallate}

Green tea is an infusion native from China and India, which is made from Camellia sinensis leaves that have not been oxidized before drying. In these leaves, the presence of between 30 and $40 \%$ of polyphenols has been estimated, and among them, epigallocatechin gallate (EGCG) or epigallocatechin-3-gallate is the most abundant catechin (145). Additionally, EGCG has been reported as the highest antioxidant activity among catechins (146). Importantly, that property is more elevated in green than black tea because of its polyphenolic content (147). The modulatory effect of EGCG on the immune system has been extensively reported, especially in $\mathrm{T}$ cells, where EGCG suppresses T-cell proliferation (148) and $\mathrm{T}_{\mathrm{H}} 1 / \mathrm{T}_{\mathrm{H}} 17$ differentiation (149) but increases Treg cell differentiation (150). Although it has not been directly associated, EGCG modulation of $\mathrm{T}$-cell response could be related to the upregulation of HO-1 and Nfr2. Epigallocatechin gallate reduces renal inflammation in a cisplatin-induced nephrotoxicity model by increasing $\mathrm{Nfr} 2$ and $\mathrm{HO}-1$ and reducing $\mathrm{NF} \kappa \mathrm{B}$ (151). However, in immune-mediated glomerulonephritis, EGCG ameliorates the inflammation without a change in renal HO-1 expression (152). Therefore, EGCG-mediated HO-1 modulation could not be involved in all pathogenic conditions. It has been shown that EGCG induces HO-1 expression and reduces transforming growth factor $\beta$ (TGF$\beta$ ) expression in macrophages (153). Furthermore, EGCG inhibits the production of proinflammatory cytokines and NO through HO-1 induction during adipocyte-macrophage interaction (154).

Importantly, a high dose of EGCG has been indicated as toxic to astrocytes, at least in part, by targeting mitochondria via calcium pathway (155). On the other hand, EGCG has some disadvantages, such as low stability and bioavailability, and its absorption at the intestine depends on the individual microbiota composition and its metabolism (156). All this entails a challenge for the application of this substance as a therapeutic agent, which is why several studies have developed and evaluated EGCG analogs with improved properties $(157,158)$.

\section{Phlorotannins}

Phlorotannins are tannins found exclusively in marine brown algae (Ochrophyta, Phaeophyceae). Interestingly, most reports focus on phlorotannins isolated from seaweeds of Ecklonia genera (Ecklonia cava). Since the 70's, more than 150 phlorotannins have been extracted from several brown seaweed, many of them with anti-inflammatories properties (159). Thus, phlorotannins from E. cava reduce the release of proinflammatory cytokines by RAW 264.7 macrophages (160) and decrease the mortality of endotoxic shock (161). These effects have been related to the activation of the $\mathrm{Nrf} 2 / \mathrm{HO}-1$ pathway (Figure 1), being dieckol the phlorotannin that presents higher anti-inflammatory properties in primary macrophages (161). Furthermore, in LPS-stimulated RAW 264.7 macrophages, E. cava ethanolic extract treatment decreased proinflammatory cytokine gene expression and inflammatory mediators, by up-regulating Nrf2/HO-1 signaling (162). Similarly, Ecklonia stolonifera ethanol extract (with phlorofucofuroeckol A and B) inhibits the Akt/ERK/JNK1-2 and p38 MAPK signaling in LPS-stimulated RAW 264.7 cells with anti-inflammatory effects (163). Also, dieckol protects RAW 264.7 cells against fine dust-induced inflammation via the $\mathrm{HO}-1 / \mathrm{Nrf} 2$ signaling activation and inducing anti-inflammatory and antioxidant mechanisms (164). Besides, dieckol up-regulates HO-1 in LPS-stimulated macrophages, which at least in part mediates its anti-inflammatory effect (165).

The phlorotannins have not shown toxicity following oral administration to mice (166), but the growth-inhibition effect has been reported in cell lines in a dose-dependent way (166). On the other hand, phlorotannins are mainly metabolized and absorbed in the large intestine and have been reported a great interindividual variation in the metabolic profile (167). Hence, more studies are needed to evaluate the effect of food matrices and processing in phlorotannins bioavailability.

\section{Celastrol}

Celastrol, also named tripterine, is a quinone methide triterpene used in traditional Chinese medicine, which is obtained from the root of the Thunder God Vine (Tripterygium wilfordii) and Celastrus regelii plant (168). Treatment with celastrol has been demonstrated to have beneficial effects in different forms of neurodegenerative, autoimmune, and inflammatory diseases. Celastrol induces HO- 1 expression in different cell lines and has been suggested to be beneficial by reducing inflammation in some chronic diseases (169). Interestingly, celastrol inhibits proinflammatory M1 polarization in RAW264.7 macrophages via regulating Nrf2/HO-1 (170). Besides, it has been shown that synthetic derivatives of natural triterpenoids exposure on DCs result in the induction of HO-1, TGF- $\beta$, and IL-10, as well as the repression of proinflammatory cytokines (171).

On the other hand, celastrol has shown a narrow window of therapeutic in vivo effect, low concentrations lack efficacy, and higher levels show signs of toxicity in different models $(172,173)$. Besides, infertility has been indicated as an important side effect of celastrol administration (174). Thus, it has been suggested that celastrol has a dual effect, suppressing oxidative stress at low concentrations, and inducing ROS at higher 
levels (175). Importantly, celastrol is poorly absorbed after oral administration in rats, and it is absorbed more efficiently by female rats as compared to males. However, bioavailability can be increased by Thunder God Vine extract administration (176), suggesting additional components in the extract aid to celastrol absorption. Hence, new celastrol analogs have been developed with higher pharmacokinetics properties and lower toxicological characteristics (175). In addition, several celastrol derivatives have been synthesized to improve its bioavailability for therapeutic administration (177).

\section{Caffeic Acid Phenethyl Ester}

Caffeic acid phenethyl ester is the ester of caffeic acid extracted from honeybee propolis, which has been used for many years in traditional medicine (178). This compound has been characterized by its strong antioxidant and cytoprotective properties, as well as immunomodulatory and anti-inflammatory attributes (179). It has been described that CAPE inhibits cytokine production by stimulated DCs (180) and suppresses DNA synthesis of human peripheral blood mononuclear cells (PBMCs) in response to mitogens (181). Besides, CAPE has been identified as a potent HO-1 activator (12), which induces $\mathrm{Nrf2}$ and in turn inhibits NFKB activation in macrophages (Figure 1) (182, 183). Caffeic acid phenethyl ester derivative compounds promote the switch of macrophage phenotypes from proinflammatory M1 to resolving M2. Besides, the effect is dependent on the activation of the Nrf2/HO-1 pathway (184). Moreover, CAPE induces HO-1 in microglia cells, reducing NO production (185).

Interestingly, new CAPE analogs have been developed that show a more potent HO-1 induction (186). In fact, it has been indicated that HO-1 up-regulation plays an essential role in the cytoprotective activity of CAPE derivatives than their antioxidant activity (187). Besides, its bioavailability has been shown to increase after glycosylation without affecting the CAPE anti-inflammatory properties (188). Propolis has a low order of acute oral toxicity (189), and importantly, no significant clinical toxicity has been reported in animals after oral propolis extract administration (190).

\section{Capsaicin}

Capsaicin (trans-8-methyl- $N$-vanillyl-6-nonenamide) is the active ingredient of chili peppers, which is found in the placental tissue that surrounds the seeds in Capsicum spp (191). This pungent oleoresin has shown strong anti-inflammatory properties $(192,193)$. The interaction of capsaicin with transient receptor potential vanilloid 1 is responsible for nociceptive, thermal, and mechanical sensations and has been shown to induce HO-1 expression (194). This receptor is present in almost all tissues, including the immune system. Moreover, it has been reported that capsaicin induces the expression of antioxidant enzymes by phosphorylation of Akt, modification of Keap1 protein, release, and translocation of Nrf2 to the nucleus and by binding to ARE elements to induce HO-1 expression (Figure 1) (195). Furthermore, it has been reported that capsaicin has therapeutic potential in renal damage by attenuation of the expression of inflammatory mediators (196). However, this effect is entirely abrogated by the treatment with the $\mathrm{HO}$ inhibitor
ZnPP (197). Moreover, capsaicin increases HO-1 expression and inhibits NO production in LPS-stimulated RAW264.7 macrophages (198).

Interestingly, although capsaicin is highly absorbed, its halflife in plasma is low, and therefore, novel drug delivery strategies have been evaluated to improve bioavailability, such as the use of capsaicin-loaded polymeric micelles (199). Importantly, capsaicin has shown both mutagenic and carcinogenic activities, but results are conflicting. Thus, other studies indicate that capsaicin possesses chemoprotective activity against some carcinogens and mutagens chemical (200). Therefore, toxicity is determined only in animals with high median lethal dose (LD50) values, and there are no reported cases of an overdose in humans (201).

\section{Garlic-Derived Organosulfur Compounds}

Organosulfur are bioactive components of garlic (Allium sativum) essential oil, mustard, asafoetida, and other food extracts (202). Worldwide, the traditional use of garlic in medicine is known for thousands of years, and multiple pharmacological properties have been reported in the literature and applied to clinical trials (203). The presence and abundance of compounds in garlic vary according to preparation and extraction (204), suggesting that there is also a wide variety of immunoregulatory properties (205). Among organosulfur present in garlic, diallyl sulfide, diallyl disulfide (DADS), and diallyl trisulfide (DATS) are the major inducers of HO-1 expression in human hepatoma HepG2 cells (206). It has been reported that DADS induces $\mathrm{Nrf}-2 / \mathrm{HO}-1$ signaling (Figure 1) and reduces proinflammatory cytokine production in LPSstimulated RAW 264.7 macrophages (207). Moreover, S-allyl cysteine (SAC), an organosulfur present in aged garlic extract, has antidiabetic, antioxidant, anti-inflammatory properties, and helps in preserving cognitive deficits in diabetic rats through the regulation of $\mathrm{Nrf} 2 / \mathrm{NF}-\mathrm{kB} / \mathrm{TLR} 4 / \mathrm{HO}-1$ signaling cascade (208). Furthermore, aged red garlic extract reduces LPS-induced NO production in RAW 264.7 macrophages, and this effect is dependent on HO-1 induction (209).

Despite toxicological data of organosulfur from garlic are limited; in vitro studies report no mutagenicity (210). Besides, oral administration of allium extracts showed no mortality or side effects in rats (211). Importantly, the beneficial effect of these compounds is closely related to its bioavailability, and therefore thermal instability of these compounds must be considered (212).

\section{Isothiocyanates}

Naturally occurring ITCs can be found in cruciferous vegetables (213). They have been evaluated as immunoregulatory and antioxidant molecules in many reports (214-216). Sulforaphane, a naturally occurring ITC from broccoli, has been demonstrated to attenuate cell damage induced by 1-methyl-4-phenyl pyridine ion $(\mathrm{MPP}+)$ in $\mathrm{PC} 12$ cells by reversing the reduced expression of Nrf2, HO-1, and NAD(P)H-quinone oxidoreductase (NQO1) (217). The beneficial effect of SFN-induced Nrf2-HO-1/NQO-1 signaling pathway activation was also demonstrated in chronic renal allograft dysfunction (Figure 1) (218). Furthermore, SFN suppresses $\mathrm{T}_{\mathrm{H}} 17$ response on untransformed human $\mathrm{T}$ cells 
by decreasing GSH and the accumulation of ROS (219). Interestingly, SFN also inhibits the inflammatory response by suppressing the cytokines response, $\mathrm{NF} \mathrm{B}$ activation, and inducing HO-1 expression in cultured monocytes and the lungs of mice (220). Besides, SFN prevents the production of NO and cytokines by activating the $\mathrm{Nrf} / \mathrm{HO}-1$ signal transduction pathway and limiting iNOS activity (221). Furthermore, SFN reduces IL-23 and IL-12 production in DCs (222).

Finally, the bioavailability of ITCs has been evaluated in broccoli sprouts and has been reported that it is highly influenced by the food structure and composition (223), without metabolites accumulation (224). Importantly, although SFN is considered safe at low doses (225), it has been reported that high doses have proconvulsant effects and produce marked sedation, hypothermia, impairment of motor coordination, and deaths (226). Despite that doses are higher than found in dietary consumption, the risk-benefit ratio of SFN administration must be considered when the diet is supplemented.

\section{HO-1, NATURAL COMPOUNDS, AND IMMUNE-MEDIATED DISEASES}

The beneficial role of $\mathrm{HO}-1$ induction in autoimmune and inflammatory disorders has been extensively reported in the last decades (227). In fact, HO-1 knockout mice develop a chronic inflammatory disease with increased peripheral blood lymphocyte count and accumulation of polymorphonuclear cells and monocytes/macrophages in the spleen (65). Consistently, a polymorphism in the hmox 1 promoter region, which regulates the HO-1 induction (228), has been associated with increased systemic lupus erythematosus (SLE) (229) and rheumatoid arthritis (RA) susceptibility (230). On the other hand, as most of the modulatory effects of $\mathrm{HO}-1$ are described on innate cells, it could be assumed that these inductors would be more efficient for the treatment of autoinflammatory diseases, especially with myeloid cell expansion. Nevertheless, HO-1 induction has also been beneficial for the treatment of autoimmune diseases mediated by $\mathrm{T}$ or $\mathrm{B}$ cells (10). In this sense, it is essential to highlight that, in the first place, the conditions described below are immersed in a scenario that involves characteristics of both autoimmune and autoinflammatory disorders (85). Second, the role of DCs as an interconnection between innate and adaptive responses is critical. Hence, as mentioned previously (Figure 2), the induction of HO-1 in DCs has been described to induce a tolerance profile in DCs (76), which in turn is capable of suppressing subsequent autoreactive responses. Therefore, the induction of HO-1 expression has been proposed as a strategy to improve autoimmune diseases (10). For this purpose, some substances of natural origin capable of triggering the overexpression of HO-1 in animal models have been evaluated in recent decades (Table $\mathbf{1}$ ).

\section{Multiple Sclerosis}

Multiple sclerosis (MS) is a demyelinating autoimmune pathology that affects the central nervous system (CNS) in humans (Figure 3) (241). Interestingly, it has been observed that $\mathrm{HO}-1$ expression is reduced in PBMCs from MS patients during exacerbation periods (242). Accordingly, CO treatment has been suggested by several in vivo preclinical studies as an effective treatment for MS (243). Dimethylfumarate (DMF), a small molecule that improves psoriasis and MS, has been reported to induce a tolerogenic profile in DCs by $\mathrm{HO}-1$ expression (244). Significant contributions aiming to understand the role of inflammation and the immune system in MS have been made using an animal model named EAE (245). Heme oxygenase 1 deficiency in mice that suffer EAE has been shown to develop an aggravated disease (246). Moreover, the protective effect of HO-1 induction has been associated with inhibition of MHC II expression by antigen-presenting cells, including DCs, microglia, and infiltrating macrophages. Importantly, inhibition of $\mathrm{CD}^{+}$and $\mathrm{CD} 8^{+} \mathrm{T}$ cell accumulation and effector function in CNS have also been reported (246). Besides, intraperitoneal CAPE administration inhibits ROS production in EAE and ameliorated clinical symptoms in rats (247). In addition, CAPE treatment possesses antineuroinflammatory effects, which are related, at least in part, to the increased expressions of $\mathrm{HO}-1$ via AMPK $\alpha$ in microglial cells (185). Besides, CAPE inhibits the expressions of iNOS, COX2, and NO production in microglia, showing an antineuroinflammatory effect (185). Importantly, quercetin mitigates inflammatory responses in microglial cells inhibiting LPS-induced NO production by HO-1 induction (96). Similarly, curcumin reduces neuroinflammation by HO-1 induction in BV-2 microglial cells and reduces iNOS and COX2 expression (108). Despite, these natural compounds have antiinflammatory effects mediated by $\mathrm{HO}-1$ in vitro in microglia, the HO- 1 contribution in the improvement associated with natural compounds has not been evaluated in models in vivo. Thus, several other natural compounds have been reported to improve MS symptoms, although a direct involvement of HO-1 induction has not been elucidated.

\section{Type 1 Diabetes}

Type 1 diabetes (T1D) is a chronic autoimmune disease characterized by the presence of islet autoantibodies and autoreactive $\mathrm{T}$ cells, pancreatic beta cell loss, and hyperglycemia (Figure 3) (248). Up-regulation of HO-1 in DCs prevented the increase in glycemia in non-obese diabetic (NOD) mice and a lower T1D incidence, suggesting it as a potential therapeutic approach for T1D treatment (249). Furthermore, a short-term induction of HO-1 promotes the recruitment of mesenchymal cells, M2 macrophages, and fibrocytes with repair properties, preventing T1D development in rats (250). Interestingly, genetic restoration of $\mathrm{HO}-1$ expression in DCs from NOD mice reduces T1D incidence highlighting their role in tolerizing autoreactive T-cells (249). It has been shown that resveratrol administration in drinking water attenuates biochemical changes associated with diabetes, and this protective role is mediated by TGF- $\beta$ reduction and HO-1 induction (235).

Additionally, resveratrol administered by gavage attenuates T1D-induced testicular oxidative stress and apoptosis by Aktmediated Nrf2 activation and Keap1 degradation (234). On the other hand, curcumin administration in STZ-induced T1D decreases the blood glucose concentration via the activation 


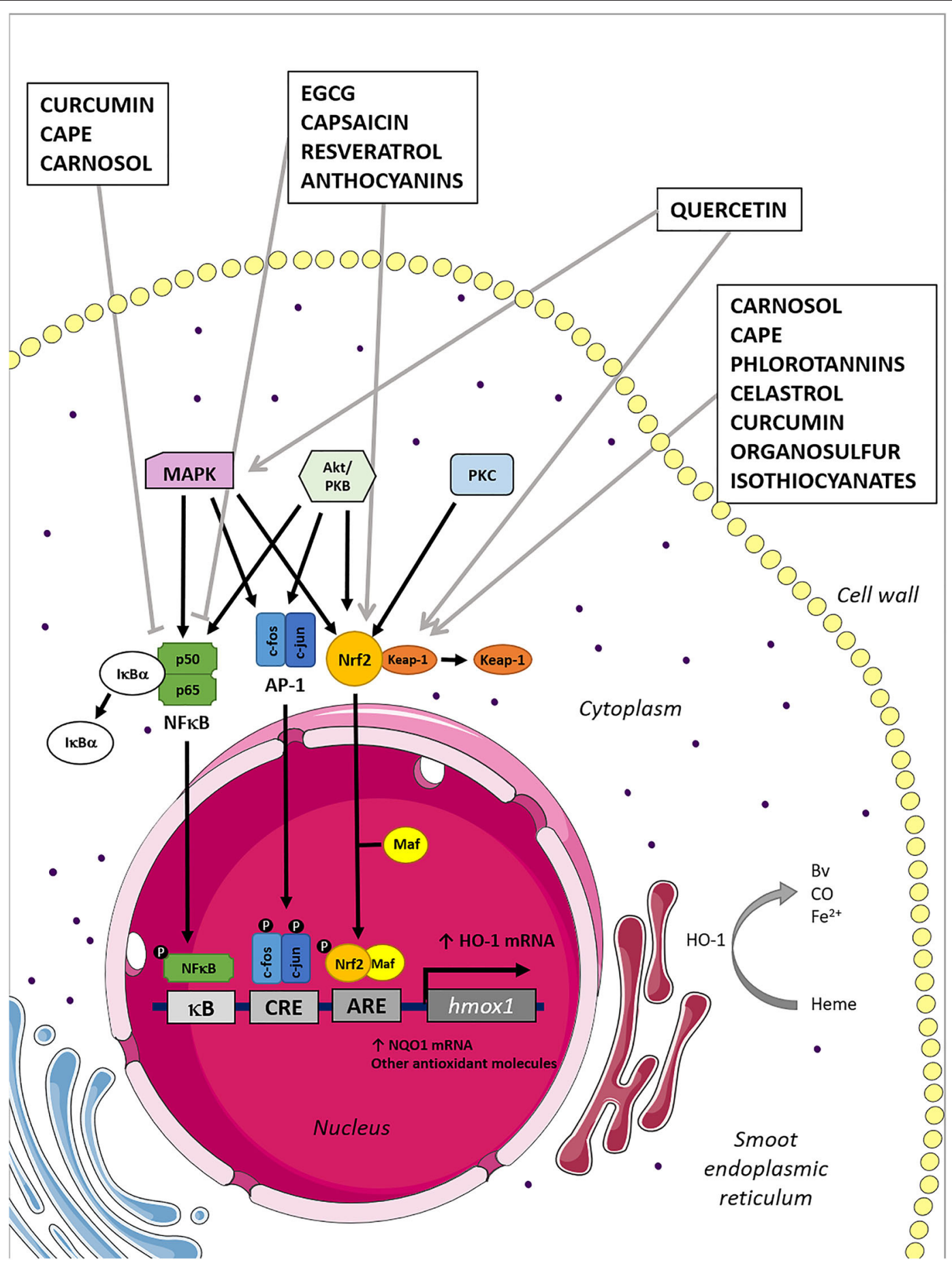

FIGURE 1 | Mechanisms of HO-1 induction by naturally derived compounds. Heme oxygenase 1 induction can be mediated by several transcription factors and their upstream kinases associated, as is graphically represented in the figure. Natural compounds inhibit/activate the transcription factors, which translocate to the nucleus promoting the $\mathrm{HO}-1$ mRNA expression. Consequently, the $\mathrm{HO}-1$ induced expression leads to the increment of their anti-inflammatory and antioxidant products: BV, $\mathrm{Fe}^{2+}$, and CO.

of the Keap1-Nrf2-AREHO-1 signaling pathway, although no immunological mechanisms were described in the study (105). In the same model, a small dose of water-soluble curcumin derivative orally administered has been shown to have antidiabetic properties mediated by HO-1 induction (232). These reports suggest that curcumin administration reduces oxidative stress in part by HO-1 induction ameliorating symptoms in T1D models. Finally, it has been proposed that appropriate DATS 


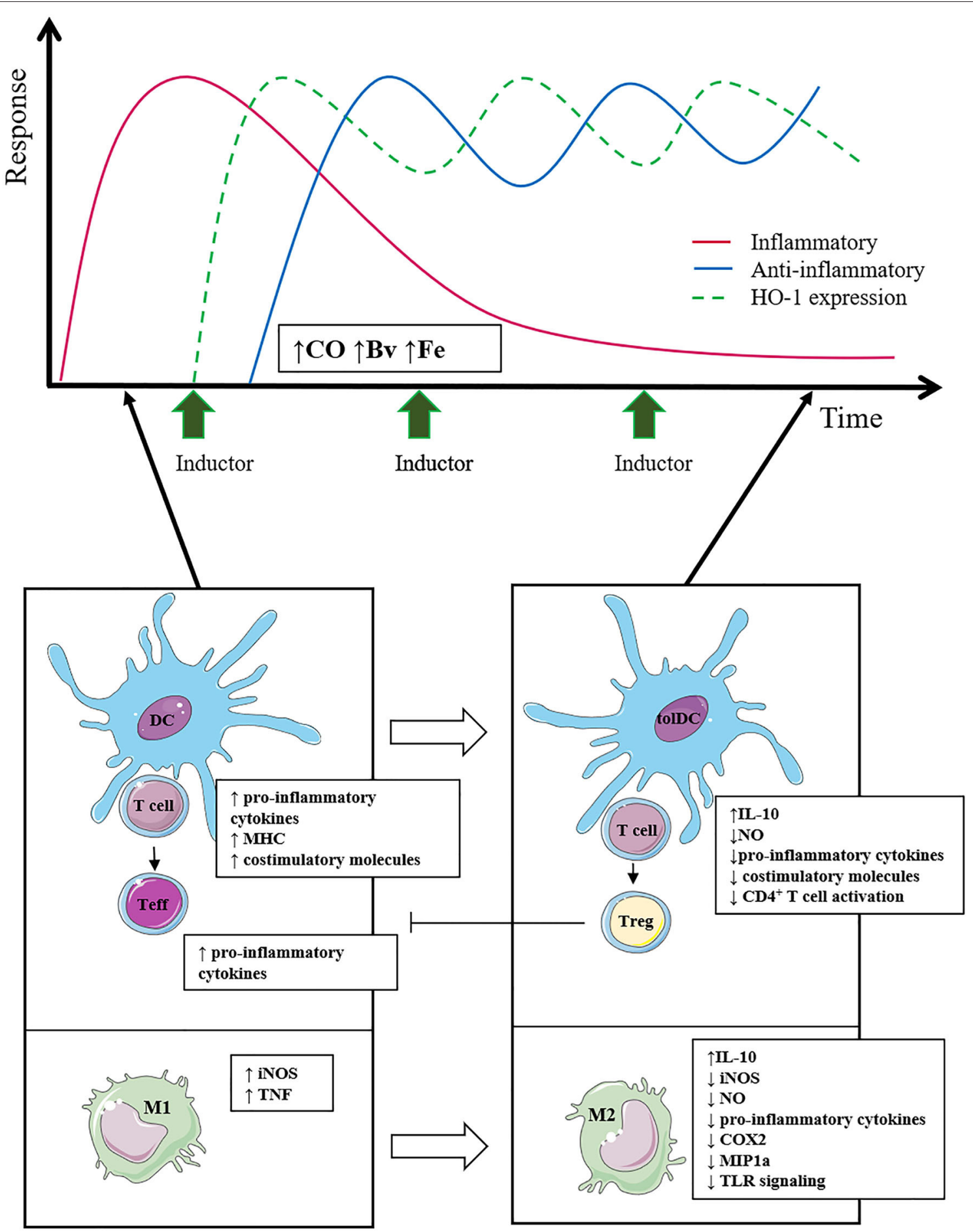

FIGURE 2 | The effect of the use of $\mathrm{HO}-1$ inducers on the inflammatory and anti-inflammatory response is outlined. Multiple inducer pulses keep HO-1 expression elevated over time (green line), whereas the anti-inflammatory response (blue line) increases accordingly. Consequently, the inflammatory response (red line) is reduced in a sustained way, managing to limit tissue damage. The induction of $\mathrm{HO}-1$ in immune cells promotes the polarization of macrophages toward the anti-inflammatory M2 profile and in turn favors a tolerogenic profile in DCs, which together reduce T-cell activation and promote Treg cell differentiation.

consumption might be a cotherapy for hyperglycemia (251). Besides, DATS perioperative intraperitoneal administration to STZ-induced T1D rats reduces injury at least in part by up-regulating the Nrf-2/HO-1 antioxidant signaling and reducing myocardial apoptosis (239). Accordingly, it has been reported that the impairment of Nrf-2/HO-1 signaling 
TABLE 1 | Natural source, evaluated model of autoimmune diseases, and reported effect of natural compounds.

\begin{tabular}{|c|c|c|c|c|}
\hline Reported compound & Natural source & Evaluated model & Reported effect & References \\
\hline \multirow[t]{2}{*}{ Quercetin } & $\begin{array}{l}\text { Fruits and vegetables } \\
\text { (particularly red onion and } \\
\text { leaves tea) }\end{array}$ & CIA mice & $\begin{array}{l}\uparrow \mathrm{HO}-1 \text { protein in synovium, } \\
\text { modulation of Th17/Treg balance, } \\
\downarrow \text { pro-inflammatory cytoquines }\end{array}$ & $(100)$ \\
\hline & & DSS-induced colitis mice & $\begin{array}{l}\uparrow \mathrm{HO}-1 \text { protein in intestinal } \\
\text { macrophages, } \uparrow \mathrm{IL}-10, \downarrow \mathrm{TNF}-\alpha \text {, } \\
\text { IFN- } \gamma, \mathrm{IL} 17 \mathrm{~A} \text {, and IL- } 6, \downarrow \text { intestinal } \\
\text { histological score }\end{array}$ & $(231)$ \\
\hline \multirow[t]{3}{*}{ Curcumin } & Curcuma Longa & STZ-induced T1D rats & $\uparrow \mathrm{HO}-1$ mRNA in liver, $\downarrow$ blood glucose & $(105)$ \\
\hline & & STZ-induced T1D rats & $\begin{array}{l}\uparrow H O-1 \text { mRNA and activity in } \\
\text { pancreas, aorta, and liver, } \downarrow \text { blood } \\
\text { glucose, } \uparrow \text { plasma insulin }\end{array}$ & $(232)$ \\
\hline & & Nephrectomized rats IBD & $\begin{array}{l}\uparrow \mathrm{HO}-1 \text { protein in kidney, } \downarrow \text { TGF- } \beta \text {, } \\
\mathrm{TNF}-\alpha \text {, and COX2 }\end{array}$ & (233) \\
\hline \multirow[t]{3}{*}{ Resveratrol } & Fruits and vegetables & STZ-induced T1D mice & $\begin{array}{l}\uparrow \mathrm{HO}-1 \mathrm{mRNA} \text { and protein in } \\
\text { testicular tissues }\end{array}$ & $(234)$ \\
\hline & & STZ-induced T1D rats & $\uparrow \mathrm{HO}-1$ protein, $\downarrow$ TGF- $\beta$ in heart & $(235)$ \\
\hline & & Osteoarthritis-induced rats & $\begin{array}{l}\uparrow \mathrm{HO}-1 \text { protein in joint tissue, } \downarrow N F-k B \\
\text { protein, } \downarrow T N F-\alpha, I L-1 \beta, I L-6 \text {, and } \\
\mathrm{IL}-18\end{array}$ & $(236)$ \\
\hline Epigallocatechin gallate (EGCG) & Green tea & DNBS-induced colitis rats & $\begin{array}{l}\uparrow \mathrm{HO}-1 \text { protein in colon, } \downarrow \mathrm{MPO} \text {, } \\
\text { ICAM- } 1 \text {, and TNF- } \alpha \downarrow \text { diarrhea }\end{array}$ & $(237)$ \\
\hline Caffeic acid phenethyl ester (CAPE) & Honeybee propolis & STZ-induced T1D rats & $\begin{array}{l}\uparrow \mathrm{HO}-1 \text { protein, } \downarrow \text { blood glucose, } \\
\uparrow \text { plasmatic insulin, } \downarrow \text { iNOS, }\end{array}$ & $(238)$ \\
\hline $\begin{array}{l}\text { Garlic-derived organosulfur } \\
\text { compounds (DAS, DADS, DATS, } \\
\text { SAC, AMS) }\end{array}$ & $\begin{array}{l}\text { Allium sativum, mustard, Ferula } \\
\text { assafoetida }\end{array}$ & STZ-induced T1D rats & $\begin{array}{l}\uparrow \mathrm{HO}-1 \text { mRNA and protein in heart, } \\
\downarrow \text { cardiac injury }\end{array}$ & (239) \\
\hline $\begin{array}{l}\text { Isothiocyanates (sulforaphane, } \\
\text { phenethyl isothiocyanate, allyl } \\
\text { isothiocyanate) }\end{array}$ & Cruciferous vegetables & DSS-induced colitis mice & $\begin{array}{l}\uparrow H O-1 \text { mRNA in colon, } \downarrow \text { clinical } \\
\text { score, } \downarrow T N F-\alpha, N O, M P O, I L-1, I L-6 \text {, } \\
\text { and iNOS }\end{array}$ & $(240)$ \\
\hline
\end{tabular}

Only studies where the HO-1 induction was evaluated are listed.

contributes to aggravated myocardial injury in STZ-induced T1D mice (252). Moreover, antihyperglycemic property of CAPE used in the STZ-induced T1D rat model has been associated to HO-1 induction (238). It is important to highlight that although various HO-1-inducing compounds have been evaluated in the context of T1D models with promising results, more studies of their effect on the immune response are necessary.

\section{Rheumatoid Arthritis}

Rheumatoid arthritis is a chronic autoimmune disease characterized by articular cartilage erosion and inflammatory cell infiltration in the joints, leading to disability (Figure 3) (253). It has been observed that HO-1 is highly increased in synovial fluid (254) and peripheral monocytes (255) from RA patients, suggesting that HO-1 expression might be an inflammation marker. In addition, $\mathrm{HO}-1$ is upregulated in the murine collagen-induced arthritis (CIA) (256) and the rat adjuvant-induced arthritis model (257). Interestingly, high levels of HO-1 could be, at least in part, an adaptive mechanism for limiting inflammation and cytotoxicity (256).

The therapeutic effect of quercetin administration by gavage has been evaluated in the CIA model showing anti-inflammatory results. Importantly, quercetin oral administration reduces arthritic manifestations in the CIA murine model, by the decrease in proinflammatory cytokines (TNF- $\alpha$, IL-1 $\beta$, IL- 6 , IL-17A, IL-21) and increase in IL-10 and TGF- $\beta$ and the restoration of $\mathrm{T}_{\mathrm{H}} 17 /$ Treg balance. Remarkably, HO-1 siRNA inhibits the beneficial effect of quercetin, suggesting a critical role of HO-1-mediated anti-inflammatory response (100). Moreover, oral resveratrol administration decreases inflammatory damage of autoinflammatory osteoarthritis in rats via $\mathrm{Nrf}-2 / \mathrm{HO}-1$ expression in joint tissue by reducing TNF- $\alpha$, IL-1 $\beta$, IL- 6 , and IL-18 expression (236).

Although beneficial effects have been reported in RA by administering natural compounds such as anthocyanin, celastrol, or garlic derived organosulfur, there is no direct association with $\mathrm{HO}-1$ induction.

\section{Systemic Lupus Erythematosus}

The SLE is a chronic autoimmune disease that could affect several organs such as kidneys, joints, skin, nervous systems, and mucosa, among others (Figure 3) (258). This disorder is characterized by the production of autoantibodies against nuclear self-antigens and immune complex deposition, which are associated with organ malfunction and injury (259). Based on the inhibitory effects of tolerogenic DCs (tolDCs) in T-cell priming and B-cell differentiation and the impact of these cells 


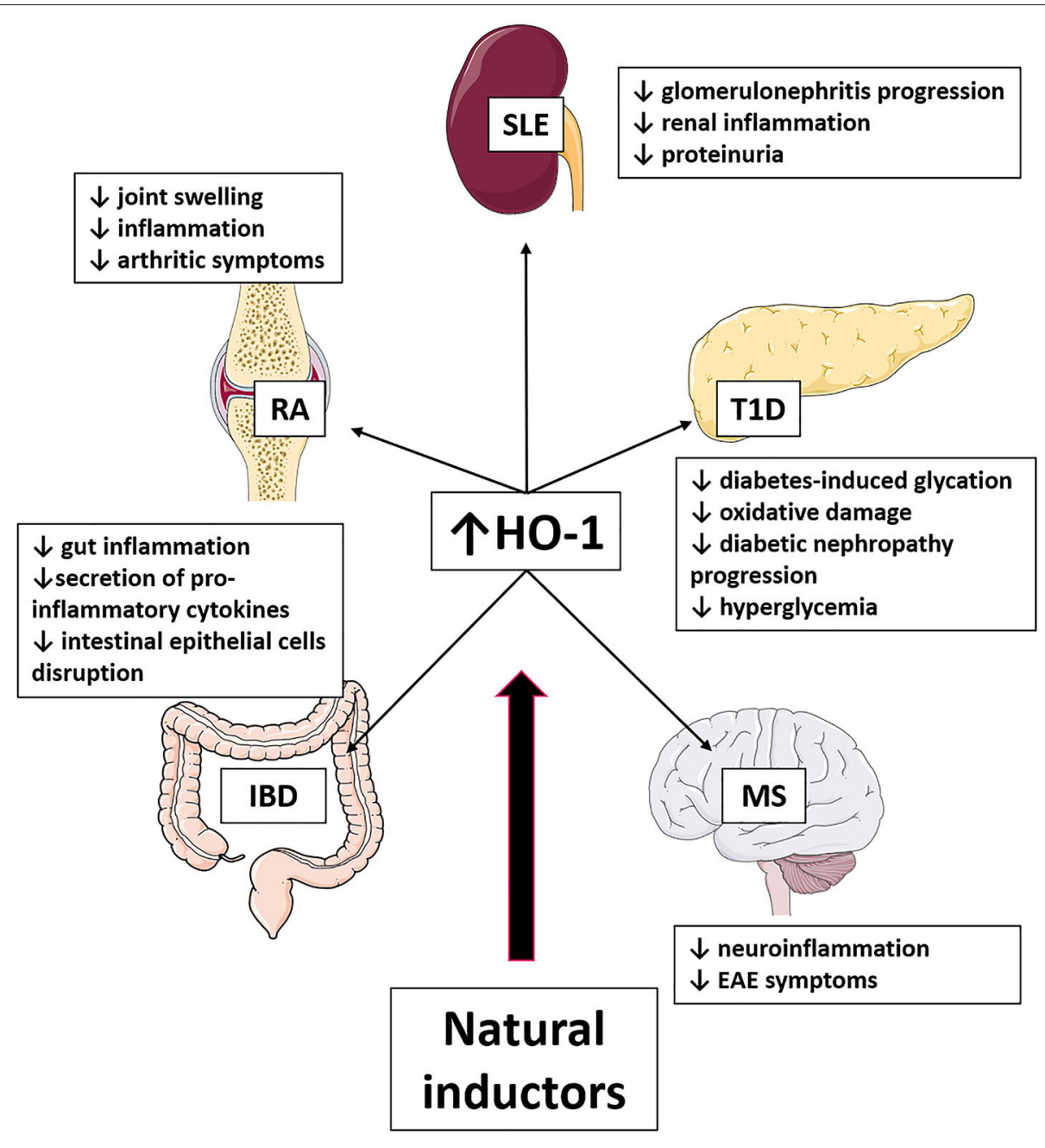

FIGURE 3 | Effect of HO-1 induction produced by natural compounds in autoimmune diseases. The use of natural inductors of HO-1 has been shown in SLE, T1D, EAE, IBD, and AR to produce the beneficial effects listed in the figure.

in maintaining peripheral tolerance (260), tolDCs administration has been suggested as a therapy in the progression of $\operatorname{SLE}(9,261)$. Accordingly, the transference of tolDC generated with HO-1 inductor cobalt (III) protoporphyrin IX (CoPP), dexamethasone, and rosiglitazone improves SLE symptoms in mice, such as decreased antinuclear antibodies, skin lesions severity, and clinical score (262).

Moreover, HO-1 induction confers an anti-inflammatory profile to monocytes and DCs, and accordingly, is less expressed in monocytes from SLE patients, suggesting that HO-1 deregulation may be involved in the development or progression of SLE (263). Therefore, CO exposure reduces the clinical score by a decrease in the expansion of $\mathrm{CD} 1 \mathrm{~b}^{+}$cells (261) and leukocyte activation in SLE mice (6). Consequently, it has been proposed that the application of $\mathrm{HO}-1$ inducers could be an appropriate therapy to ameliorate SLE conditions. For example, a diet with extra virgin olive oil was shown to improve renal damage in an SLE model in mice through the induction of $\mathrm{Nrf}-2 / \mathrm{HO}-1$ expression and reduction of proinflammatory cytokines by splenocytes (264). Besides, oral curcumin administration reduces renal fibrosis and inflammation mediated by $\mathrm{Nrf} 2$ and $\mathrm{HO}-1$ induction in nephrectomized rats (233). However, further studies are needed to elucidate the precise role of $\mathrm{HO}-1$ in quercetin, resveratrol, and celastrol-lupus amelioration.

\section{Inflammatory Bowel Disease}

Among chronic inflammatory bowel diseases (IBDs) are Crohn disease (CD) and ulcerative colitis (UC), which are characterized by symptoms of diarrhea, abdominal pain, and the presence of blood in the stool (Figure 3). Both UC and CD are considered polygenic autoinflammatory diseases (85). Although CD involves inflammation at any gastrointestinal section, UC is restricted to colonic inflammation. Recently, several studies have suggested that HO-1 and its products could have an critical role in the modulation and progression of IBD (11). The pharmacological induction of HO-1 has been extensively reported to reduce gut inflammation by anti-inflammatory cytokines (11). Thus, 
in the model of UC triggered by the administration of dextran sulfate sodium (DSS), the induction of HO-1 by CoPP or hydrogen-rich water reduces the intestinal histological damage $(265,266)$. Thus, a significant reduction in TNF- $\alpha$, IL-6, and IL$1 \beta$ proinflammatory cytokines has been reported (266). Besides, some drugs such as tranilast, Atractylodes macrocephala, or Taraxacum herb extracts, which ameliorate symptoms in IBD patients and exert their effect by inducing HO-1 expression (11).

In a recent study, it was observed that oral quercetin ameliorates T-cell-mediated UC, reduces gut inflammation, and modulates intestinal macrophages inducing an antiinflammatory $\mathrm{M} 2$ profile and inhibiting $\mathrm{CD} 4^{+} \mathrm{T}$ cell activation (231). Importantly, macrophage depletion partially blockades the beneficial effect of quercetin in gut inflammation, highlighting the role of these cells in intestinal homeostasis (231). Moreover, curcumin protects human intestinal epithelial cell disruption and barrier dysfunction via HO-1 induction (267). Also, green tea administration up-regulates HO-1 expression in the colon, which may contribute to the protective effects in 2,4,6-dinitrobenzenesulphonic acid-induced colitis model by reduction of colonic myeloperoxidase (MPO) and TNF- $\alpha$ production (237). Interestingly, it has been reported that both resveratrol and $\mathrm{C} 3 \mathrm{G}$ induce $\mathrm{HO}-1$ in $\mathrm{HT}-29$ intestinal cells, which may interfere with the expression of proinflammatory enzymes (268). Thus, HO-1 induction has been suggested as a putative molecular mechanism associated, at least in part, to the therapeutic effect of resveratrol. On the other hand, the gavage administration of ITCs in the DSS-induced colitis model ameliorates the severity of the disease, mediated by Nrf2 and HO-1 anti-inflammatory/antioxidant signaling pathway (240). Importantly, ITC administration decreases colonic secretions of proinflammatory TNF- $\alpha, \mathrm{NO}$, and MPO in UC, besides reducing gene expression of IL-1, IL-6, TNF- $\alpha$, and iNOS (240). Hence, IBD characterized by self-directed inflammation, where the activation of innate immune cells plays a critical role in pathogenesis, appears to be a particularly promising target for the implementation of HO-1 inducers as immunomodulators.

\section{CONCLUDING REMARKS}

Heme oxygenase 1 induction has been suggested as a therapeutic approach to ameliorate self-directed immune diseases, including both autoimmune and autoinflammatory diseases. Accordingly, many dietary and herbal medicines that induce HO-1 expression

\section{REFERENCES}

1. Tenhunen R, Marver HS, Schmid R. The enzymatic conversion of heme to bilirubin by microsomal heme oxygenase. Proc Natl Acad Sci USA. (1968) 61:748-55. doi: 10.1073/pnas.61.2.748

2. Maines MD, Kappas A. Cobalt induction of hepatic heme oxygenase; with evidence that cytochrome P-450 is not essential for this enzyme activity. Proc Natl Acad Sci USA. (1974) 71:4293-7. doi: 10.1073/pnas.71.11. 4293

3. Maines MD, Trakshel G, Kutty RK. Characterization of two constitutive forms of rat liver microsomal heme oxygenase. Only one molecular species of the enzyme is inducible. Biol Chem. (1986) 261:411-9. have been widely evaluated as a possible strategy to improve autoimmunity. Thus, consumption of spicy food, tea, or red wine might modulate immune responses. However, it is crucial to consider the bioavailability, absorption, toxicity, and metabolism of these compounds, as well as reported discrepancy among cell culture assays and in vivo results. Furthermore, the whole picture during a classical immune response, a self-reactive response, or an exacerbated inflammation continues to be a significant debt in HO-1 scientific research.

It is important to note that most HO-1-inducing compounds have been associated with a certain degree of toxicity, especially in studies in vitro. In the case of the heme group, a nocive event leads to reduce excessive inflammation and maintain homeostasis. Thus, and taking into account also the bivalent immunosuppressant/toxic nature of the HO-1 reaction products, a more exhaustive study of the inducer doses in vivo is necessary.

Experimental data evidencing worthy properties of bioactive substances (from plants and other natural sources), which induce HO-1 expression is continuously increasing. Nevertheless, a critical evaluation of the literature data is essential, first because the majority of studies are conducted on in vitro models, and thus, it is crucial to test natural HO-1 inducers in different in vivo models, and second, because most studies highlight their experimental results underestimating the detailed report in chemical obtention methods for single molecules from food extracts, impaired reproducibility, and delay in its wide prescription.

\section{AUTHOR CONTRIBUTIONS}

SF, MR, AF-F, and CC wrote the manuscript. CR, SB, JM-O, and $A K$ proofread the manuscript and corrected language use. SF constructed the figures. AK supervised the work and performed critical revision of the manuscript. All authors revised and approved the manuscript.

\section{FUNDING}

This work was supported by Corporación de Fomento de la Producción (CORFO) Grant No. 13CTI-21526/P3 and the Millennium Institute on Immunology and Immunotherapy (P09016-F). AK is a Helen C. Levitt Visiting Professor at the Department of Microbiology and Immunology of the University of Iowa.
4. Prawan A, Kundu JK, Surh Y-J. Molecular basis of heme oxygenase1 induction: implications for chemoprevention and chemoprotection. Antioxid Redox Sign. (2005) 7:1688-703. doi: 10.1089/ars.2005. 7.1688

5. Paine A, Eiz-Vesper B, Blasczyk R, Immenschuh S. Signaling to heme oxygenase-1 and its anti-inflammatory therapeutic potential. Biochem Pharmacol. (2010) 80:1895-903. doi: 10.1016/j.bcp.2010.07.014

6. Mackern-Oberti J, Obreque J, Méndez G, Llanos C, Kalergis A. Carbon monoxide inhibits $\mathrm{T}$ cell activation in target organs during systemic lupus erythematosus. Clin Exp Immunol. (2015) 182:1-13. doi: 10.1111/cei.12657

7. Ferrandiz M, Devesa I. Inducers of heme oxygenase-1. Curr Pharm Des. (2008) 14:473-86. doi: 10.2174/138161208783597399 
8. Riquelme SA, Carreño LJ, Espinoza JA, Mackern-Oberti JP, Alvarez-Lobos MM, Riedel CA, et al. Modulation of antigen processing by haem-oxygenase 1. Implications on inflammation and tolerance. Immunology. (2016) 149:112. doi: 10.1111/imm.12605

9. Funes SC, Manrique de Lara A, Altamirano-Lagos MJ, MackernOberti JP, Escobar-Vera J, Kalergis AM. Immune checkpoints and the regulation of tolerogenicity in dendritic cells: implications for autoimmunity and immunotherapy. Autoimmun Rev. (2019) 158:32239. doi: 10.1016/j.autrev.2019.02.006

10. Mackern-Oberti JP, Riquelme SA, Llanos C, Schmidt CB, Simon T, Anegon I, et al. Heme oxygenase-1 as a target for the design of gene and pharmaceutical therapies for autoimmune diseases. Curr Gene Ther. (2014) 14:218-35. doi: 10.2174/1566523214666140424150308

11. Sebastián VP, Salazar GA, Coronado-Arrázola I, Schultz BM, Vallejos OP, Berkowitz L, et al. Heme oxygenase-1 as a modulator of intestinal inflammation development and progression. Front Immunol. (2018) 9:1956. doi: 10.3389/fimmu.2018.01956

12. Balogun E, Hoque M, Pengfei G, Killeen E, Green CJ, Foresti R, et al. Curcumin activates the haem oxygenase-1 gene via regulation of Nrf2 and the antioxidant-responsive element. Biochem J. (2003) 371:88795. doi: 10.1042/bj20021619

13. Alam J. Multiple elements within the 5'distal enhancer of the mouse heme oxygenase-1 gene mediate induction by heavy metals. Biol Chem. (1994) 269:25049-56.

14. Alam J, Cook J. Transcriptional regulation of the heme oxygenase-1 gene via the stress response element pathway. Curr Pharm Des. (2003) 9:2499511. doi: $10.2174 / 1381612033453730$

15. Zhang X, Bedard EL, Potter R, Zhong R, Alam J, Choi AM, et al. Mitogenactivated protein kinases regulate HO-1 gene transcription after ischemiareperfusion lung injury. Am J Physiol Lung Cell Mol Physiol. (2002) 283:L815-29. doi: 10.1152/ajplung.00485.2001

16. Sun J, Brand M, Zenke Y, Tashiro S, Groudine M, Igarashi K. Heme regulates the dynamic exchange of Bach1 and NF-E2-related factors in the Maf transcription factor network. Proc Natl Acad Sci USA. (2004) 101:14616. doi: 10.1073/pnas.0308083100

17. Jaiswal AK. Nrf2 signaling in coordinated activation of antioxidant gene expression. Free Radical Biol Med. (2004) 36:1199-207. doi: 10.1016/j.freeradbiomed.2004.02.074

18. Kimura M, Yamamoto T, Zhang J, Itoh K, Kyo M, Kamiya T, et al. Molecular basis distinguishing the DNA binding profile of Nrf2-Maf heterodimer from that of Maf homodimer. Biol Chem. (2007) 282:3368190. doi: 10.1074/jbc.M706863200

19. Lee J-S, Surh Y-J. Nrf2 as a novel molecular target for chemoprevention. Cancer Lett. (2005) 224:171-84. doi: 10.1016/j.canlet.2004. 09.042

20. Kwak M-K, Wakabayashi N, Kensler TW. Chemoprevention through the Keap1-Nrf2 signaling pathway by phase 2 enzyme inducers. Mutat Res. (2004) 555:133-48. doi: 10.1016/j.mrfmmm.2004.06.041

21. Itoh K, Wakabayashi N, Katoh Y, Ishii T, Igarashi K, Engel JD, et al. Keap1 represses nuclear activation of antioxidant responsive elements by Nrf2 through binding to the amino-terminal Neh2 domain. Genes Dev. (1999) 13:76-86. doi: 10.1101/gad.13.1.76

22. Reichard JF, Motz GT, Puga A. Heme oxygenase-1 induction by NRF2 requires inactivation of the transcriptional repressor BACH1. Nucleic Acids Res. (2007) 35:7074-86. doi: 10.1093/nar/gkm638

23. Ogawa K, Sun J, Taketani S, Nakajima O, Nishitani C, Sassa S, et al. Heme mediates derepression of Maf recognition element through direct binding to transcription repressor Bach1. EMBO J. (2001) 20:283543. doi: 10.1093/emboj/20.11.2835

24. Karin M, Liu Z-g, Zandi E. AP-1 function and regulation. Curr Opin Cell Biol. (1997) 9:240-6. doi: 10.1016/S0955-0674(97)80068-3

25. Das M, Sabio G, Jiang F, Rincon M, Flavell RA, Davis RJ. Induction of hepatitis by JNK-mediated expression of TNF-alpha. Cell. (2009) 136:24960. doi: 10.1016/j.cell.2008.11.017

26. Newton K, Dixit VM. Signaling in innate immunity and inflammation. Cold Spring Harb Perspect Biol. (2012) 4:a006049. doi: 10.1101/cshperspect.a006049
27. Alam J, Den Z. Distal AP-1 binding sites mediate basal level enhancement and TPA induction of the mouse heme oxygenase-1 gene. Biol Chem. (1992) 267:21894-900.

28. Lee Y-J, Beak S-Y, Choi I, Sung J-S. Quercetin and its metabolites protect hepatocytes against ethanol-induced oxidative stress by activation of Nrf2 and AP-1. Food Sci Biotechnol. (2018) 27:809-17. doi: 10.1007/s10068-017-0287-8

29. Camhi SL, Alam J, Otterbein L, Sylvester SL, Choi A. Induction of heme oxygenase-1 gene expression by lipopolysaccharide is mediated by AP-1 activation. Am J Respir Cell Mol Biol. (1995) 13:387-98. doi: 10.1165/ajrcmb.13.4.7546768

30. Alam J, Cook JL. How many transcription factors does it take to turn on the heme oxygenase-1 gene? Am J Respir Cell Mol Biol. (2007) 36:16674. doi: $10.1165 / \mathrm{rcmb} .2006-0340 \mathrm{TR}$

31. Ha YM, Ham SA, Kim YM, Lee YS, Kim HJ, Seo HG, et al. $\beta 1$ adrenergic receptor-mediated HO-1 induction, via PI3K and p38 MAPK, by isoproterenol in RAW 264.7 cells leads to inhibition of HMGB1 release in LPS-activated RAW 264.7 cells and increases in survival rate of CLP-induced septic mice. Biochem Pharmacol. (2011). 82:76977. doi: 10.1016/j.bcp.2011.06.041

32. Park EJ, Kim YM, Park SW, Kim HJ, Lee JH, Lee D-U, et al. Induction of HO-1 through p38 MAPK/Nrf2 signaling pathway by ethanol extract of Inula helenium L. reduces inflammation in LPS-activated RAW 264.7 cells and CLP-induced septic mice. Food Chem Toxicol. (2013) 55:38695. doi: 10.1016/j.fct.2012.12.027

33. Kim HS, Park EJ, Park SW, Kim HJ, Chang KC. A tetrahydroisoquinoline alkaloid THI-28 reduces LPS-induced HMGB1 and diminishes organ injury in septic mice through p38 and $\mathrm{PI} 3 \mathrm{~K} / \mathrm{Nrf} 2 / \mathrm{HO}-1$ signals. Int Immunopharmacol. (2013) 17:684-92. doi: 10.1016/j.intimp.2013. 08.016

34. Zhou M-M, Zhang W-Y, Li R-J, Guo C, Wei S-S, Tian X-M, et al. Anti-inflammatory activity of Khayandirobilide A from Khaya senegalensis via NF- $\kappa$, AP-1 and p38 MAPK/Nrf2/HO-1 signaling pathways in lipopolysaccharide-stimulated RAW 264.7 and BV-2 cells. Phytomed. (2018) 42:152-63. doi: 10.1016/j.phymed.2018.03.016

35. Naidu S, Vijayan V, Santoso S, Kietzmann T, Immenschuh S. Inhibition and genetic deficiency of p38 MAPK up-regulates heme oxygenase-1 gene expression via Nrf2. Immunol. (2009) 182:7048-57. doi: 10.4049/jimmunol.0900006

36. Abdelbaset-Ismail A, Cymer M, Borkowska-Rzeszotek S, BrzezniakiewiczJanus K, Rameshwar P, Kakar SS, et al. Bioactive phospholipids enhance migration and adhesion of human leukemic cells by inhibiting heme oxygenase 1 (HO-1) and inducible nitric oxygenase synthase (iNOS) in a p38 MAPK-dependent manner. Stem Cell Rev Rep. (2019) 15:13954. doi: 10.1007/s12015-018-9853-6

37. Li KK, Shen SS, Deng X, Shiu HT, Siu WS, Leung PC, et al. Dihydrofisetin exerts its anti-inflammatory effects associated with suppressing ERK/p38 MAPK and heme oxygenase-1 activation in lipopolysaccharide-stimulated RAW 264.7 macrophages and carrageenan-induced mice paw edema. Int Immunopharmacol. (2018) 54:366-74. doi: 10.1016/j.intimp.2017. 11.034

38. Nemmiche S, Chabane-Sari D, Kadri M, Guiraud P. Cadmiuminduced apoptosis in the BJAB human $\mathrm{B}$ cell line: involvement of $\mathrm{PKC/ERK1/2/JNK} \mathrm{signaling} \mathrm{pathways} \mathrm{in} \mathrm{HO-1} \mathrm{expression.} \mathrm{Toxicol.}$ (2012) 300:103-11. doi: 10.1016/j.tox.2012.05.003

39. Jeong Y-H, Hyun J-W, Kim Van Le T, Kim D-H, Kim H-S. Kalopanaxsaponin A exerts anti-inflammatory effects in lipopolysaccharide-stimulated microglia via inhibition of JNK and NF-кB/AP-1 pathways. Biomol Ther. (2013) 21:332-7. doi: 10.4062/biomolther.2013.069

40. Subedi L, Lee JH, Yumnam S, Ji E, Kim SY. Anti-inflammatory effect of sulforaphane on LPS-activated microglia potentially through JNK/AP-1/NF-кB inhibition and Nrf2/HO-1 activation. Cells. (2019) 8:194. doi: 10.3390/cells8020194

41. Yeligar SM, Machida K, Kalra VK. Ethanol-induced HO-1 and NQO1 are differentially regulated by HIF-1 $\alpha$ and Nrf2 to attenuate inflammatory cytokine expression. Biol Chem. (2010) 285:35359-73. doi: 10.1074/jbc.M110.138636 
42. Li C, Yang F, Liu F, Li D, Yang T. NRF2/HO-1 activation via ERK pathway involved in the anti-neuroinflammatory effect of astragaloside IV in LPS induced microglial cells. Neurosci Lett. (2018) 666:10410. doi: 10.1016/j.neulet.2017.12.039

43. Lee I-S, Ryu D-K, Lim J, Cho S, Kang BY, Choi HJ. Artesunate activates Nrf2 pathway-driven anti-inflammatory potential through ERK signaling in microglial BV2 cells. Neurosci Lett. (2012) 509:17-21. doi: 10.1016/j.neulet.2011.12.034

44. Han D, Chen W, Gu X, Shan R, Zou J, Liu G, et al. Cytoprotective effect of chlorogenic acid against hydrogen peroxide-induced oxidative stress in MC3T3-E1 cells through PI3K/Akt-mediated Nrf2/HO-1 signaling pathway. Oncotarget. (2017) 8:14680-92. doi: 10.18632/oncotarget.14747

45. Zhuang S, Yu R, Zhong J, Liu P, Liu Z. Rhein from Rheum rhabarbarum inhibits hydrogen-peroxide-induced oxidative stress in intestinal epithelial cells partly through PI3K/Akt-mediated Nrf2/HO-1 pathways. J Agric Food Chem. (2019) 67:2519-29. doi: 10.1021/acs.jafc.9b00037

46. Ye J, Piao H, Jiang J, Jin G, Zheng M, Yang J, et al. Polydatin inhibits mast cell-mediated allergic inflammation by targeting PI3K/Akt, MAPK, NF-кB and Nrf2/HO-1 pathways. Sci Rep. (2017) 7:1-13. doi: 10.1038/s41598-017-12252-3

47. Li H, Min J, Mao X, Wang X, Yang Y, Chen Y. Edaravone ameliorates experimental autoimmune thyroiditis in rats through HO-1-dependent STAT3/PI3K/Akt pathway. Am J Transl Res. (2018) 10:2037-46. doi: 10.1007/s11011-019-00532-y

48. Kundu J, Kim D-H, Kundu JK, Chun K-S. Thymoquinone induces heme oxygenase-1 expression in HaCaT cells via Nrf2/ARE activation: Akt and AMPK $\alpha$ as upstream targets. Food Chem Toxicol. (2014) 65:1826. doi: 10.1016/j.fct.2013.12.015

49. Jung J-S, Choi M-J, Lee YY, Moon B-I, Park J-S, Kim H-S. Suppression of lipopolysaccharide-induced neuroinflammation by morin via MAPK, PI3K/Akt, and PKA/HO-1 signaling pathway modulation. J Agric Food Chem. (2017) 65:373-82. doi: 10.1021/acs.jafc.6b05147

50. Li C, Li L, Jin L, Yuan J. Heme oxygenase-1 inhibits spring viremia of carp virus replication through carbon monoxide mediated cyclic GMP/Protein kinase G signaling pathway. Fish Shellfish Immunol. (2018) 79:65-72. doi: 10.1016/j.fsi.2018.05.014

51. Kim KM, Heo DR, Kim Y-A, Lee J, Kim NS, Bang O-S. Coniferaldehyde inhibits LPS-induced apoptosis through the PKC $\alpha / \beta$ II/Nrf-2/HO1 dependent pathway in RAW264.7 macrophage cells. Environ Toxicol Pharmacol. (2016) 48:85-93. doi: 10.1016/j.etap.2016. 10.016

52. Krönke G, Bochkov VN, Huber J, Gruber F, Blüml S, Fürnkranz A, et al. Oxidized phospholipids induce expression of human heme oxygenase-1 involving activation of cAMP-responsive element-binding protein. $J$ Biol Chem. (2003) 278:51006-14. doi: 10.1074/jbc.M304103200

53. Terry CM, Clikeman JA, Hoidal JR, Callahan KS. TNF- $\alpha$ and IL- $1 \alpha$ induce heme oxygenase- 1 via protein kinase $\mathrm{C}, \mathrm{Ca} 2+$, and phospholipase A2 in endothelial cells. Am J Physiol Heart Circ Physiol. (1999) 276:H1493501. doi: 10.1152/ajpheart.1999.276.5.H1493

54. Immenschuh S, Hinke V, Ohlmann A, Gifhorn-katz S, Katz N, Jungermann $\mathrm{K}$, et al. Transcriptional activation of the haem oxygenase-1 gene by cGMP via a cAMP response element/activator protein-1 element in primary cultures of rat hepatocytes. Biochem J. (1998) 334:1416. doi: 10.1042/bj3340141

55. Immenschuh S, Kietzmann T, Hinke V, Wiederhold M, Katz N, MullerEberhard U. The rat heme oxygenase-1 gene is transcriptionally induced via the protein kinase A signaling pathway in rat hepatocyte cultures. Mol Pharmacol. (1998) 53:483-91. doi: 10.1124/mol.53.3.483

56. Li B, Carey M, Workman JL. The role of chromatin during transcription. Cell. (2007) 128:707-19. doi: 10.1016/j.cell.2007.01.015

57. Zhang Z, Guo Z, Zhan Y, Li H, Wu S. Role of histone acetylation in activation of nuclear factor erythroid 2-related factor 2/heme oxygenase 1 pathway by manganese chloride. Toxicol Appl Pharmacol. (2017) 336:94100. doi: 10.1016/j.taap.2017.10.011

58. Garapati SV, Mahavadi P, Henke M, Guenther A, Chillappagari SP. Altered toll-like receptor 4 and histone deacetylase 2 expression in CFBE41o-cells regulates hemeoxygenase I via nuclear factor erythroid 2-related factor 2. Am J Respir Crit Care Med. (2016) 193:A5560.
59. Ray PD, Huang B-W, Tsuji Y. Coordinated regulation of Nrf2 and histone $\mathrm{H} 3$ serine 10 phosphorylation in arsenite-activated transcription of the human heme oxygenase-1 gene. Biochim Biophys Acta Gene Regulat Mech. (2015) 1849:1277-88. doi: 10.1016/j.bbagrm.2015.08.004

60. Kästle M, Woschee E, Grune T. Histone deacetylase 6 (HDAC6) plays a crucial role in p38MAPK-dependent induction of heme oxygenase-1 (HO-1) in response to proteasome inhibition. J Free Radical Biol. (2012) 53:2092101. doi: 10.1016/j.freeradbiomed.2012.09.023

61. Li B, Li X, Zhu B, Zhang X, Wang Y, Xu Y, et al. Sodium arsenite induced reactive oxygen species generation, nuclear factor (erythroid-2 related) factor 2 activation, heme oxygenase- 1 expression, and glutathione elevation in Chang human hepatocytes. Environ Toxicol. (2013) 28:40110. doi: 10.1002/tox.20731

62. Kapturczak MH, Wasserfall C, Brusko T, Campbell-Thompson M, Ellis TM, Atkinson MA, et al. Heme oxygenase-1 modulates early inflammatory responses: evidence from the heme oxygenase-1-deficient mouse. Am J Pathol. (2004) 165:1045-53. doi: 10.1016/S0002-9440(10)63365-2

63. Poss KD, Tonegawa S. Reduced stress defense in heme oxygenase 1-deficient cells. Proc Natl Acad Sci USA. (1997) 94:10925-30. doi: 10.1073/pnas.94.20.10925

64. Soares MP, Marguti I, Cunha A, Larsen R. Immunoregulatory effects of HO-1: how does it work? Curr Opin Pharmacol. (2009) 9:4829. doi: 10.1016/j.coph.2009.05.008

65. Poss KD, Tonegawa S. Heme oxygenase 1 is required for mammalian iron reutilization. Proc Natl Acad Sci USA. (1997) 94:10919-24. doi: 10.1073/pnas.94.20.10919

66. Figueiredo RT, Fernandez PL, Mourao-Sa DS, Porto BN, Dutra FF, Alves LS, et al. Characterization of heme as activator of Toll-like receptor 4. J Biol Chem. (2007) 282:20221-9. doi: 10.1074/jbc.M610737200

67. Vijayan V, Wagener FA, Immenschuh S. The macrophage heme-heme oxygenase-1 system and its role in inflammation. Biochem Pharmacol. (2018) 153:159-67. doi: 10.1016/j.bcp.2018.02.010

68. Naito Y, Takagi T, Higashimura Y. Heme oxygenase-1 and antiinflammatory M2 macrophages. Arch Biochem Biophys. (2014) 564:838. doi: 10.1016/j.abb.2014.09.005

69. Tzima S, Victoratos P, Kranidioti K, Alexiou M, Kollias G. Myeloid heme oxygenase -1 regulates innate immunity and autoimmunity by modulating IFN- $\beta$ production. J Exp Med. (2009) 206:1167-79. doi: 10.1084/jem.20081582

70. Nakahira K, Kim HP, Geng XH, Nakao A, Wang X, Murase N, et al. Carbon monoxide differentially inhibits TLR signaling pathways by regulating ROSinduced trafficking of TLRs to lipid rafts. J Exp Med. (2006) 203:237789. doi: 10.1084/jem.20060845

71. Takamiya R, Hung C-C, Hall SR, Fukunaga K, Nagaishi T, Maeno T, et al. High-mobility group box 1 contributes to lethality of endotoxemia in heme oxygenase-1-deficient mice. Am J Respir Cell Mol Biol. (2009) 41:129-35. doi: 10.1165/rcmb.2008-0331OC

72. Rémy S, Blancou P, Tesson L, Tardif V, Brion R, Royer PJ, et al. Carbon monoxide inhibits TLR-induced dendritic cell immunogenicity. J Immunol. (2009) 182:1877-84. doi: 10.4049/jimmunol.0802436

73. Otterbein LE, Bach FH, Alam J, Soares M, Lu HT, Wysk M, et al. Carbon monoxide has anti-inflammatory effects involving the mitogen-activated protein kinase pathway. Nat Med. (2000) 6:422-8. doi: 10.1038/74680

74. Takamiya R, Murakami M, Kajimura M, Goda N, Makino N, Takamiya $\mathrm{Y}$, et al. Stabilization of mast cells by heme oxygenase-1: an antiinflammatory role. Am J Physiol Heart Circ Physiol. (2002) 283:H86170. doi: 10.1152/ajpheart.00740.2001

75. Wong T-H, Chen H-A, Gau R-J, Yen J-H, Suen J-L. Heme oxygenase1-expressing dendritic cells promote Foxp3+ regulatory $\mathrm{T}$ cell differentiation and induce less severe airway inflammation in murine models. PLoS ONE. (2016) 11:e0168919. doi: 10.1371/journal.pone. 0168919

76. Chauveau C, Rémy S, Royer PJ, Hill M, Tanguy-Royer S, Hubert F-X, et al. Heme oxygenase-1 expression inhibits dendritic cell maturation and proinflammatory function but conserves IL-10 expression. J Blood. (2005) 106:1694-702. doi: 10.1182/blood-2005-02-0494

77. Burt TD, Seu L, Mold JE, Kappas A, McCune JM. Naive human $\mathrm{T}$ cells are activated and proliferate in response to the heme 
oxygenase-1 inhibitor tin mesoporphyrin. J Immunol. (2010) 185:5279-88. doi: 10.4049/jimmunol.0903127

78. Pae H-O, Oh G-S, Choi B-M, Chae S-C, Kim Y-M, Chung K-R, et al. Carbon monoxide produced by heme oxygenase-1 suppresses $\mathrm{T}$ cell proliferation via inhibition of IL-2 production. J Immunol. (2004) 172:474451. doi: 10.4049/jimmunol.172.8.4744

79. Choi B-M, Pae H-O, Jeong Y-R, Kim Y-M, Chung H-T. Critical role of heme oxygenase-1 in Foxp3-mediated immune suppression. Biochem Biophys Res Commun. (2005) 327:1066-71. doi: 10.1016/j.bbrc.2004.12.106

80. Zelenay S, Chora A, Soares MP, Demengeot J. Heme oxygenase-1 is not required for mouse regulatory $\mathrm{T}$ cell development and function. Int Immunol. (2007) 19:11-8. doi: 10.1093/intimm/dxl116

81. George JF, Braun A, Brusko TM, Joseph R, Bolisetty S, Wasserfall CH, et al. Suppression by CD4+ CD25+ regulatory $\mathrm{T}$ cells is dependent on expression of heme oxygenase-1 in antigen-presenting cells. Am J Pathol. (2008) 173:154-60. doi: 10.2353/ajpath.2008.070963

82. Liu Y, Li P, Lu J, Xiong W, Oger J, Tetzlaff W, et al. Bilirubin possesses powerful immunomodulatory activity and suppresses experimental autoimmune encephalomyelitis. J Immunol. (2008) 181:1887-97. doi: 10.4049/jimmunol.181.3.1887

83. Yamashita K, McDaid J, öllinger R, Tsui T-Y, Berberat PO, Usheva A, et al. Biliverdin, a natural product of heme catabolism, induces tolerance to cardiac allografts. FASEB J. (2004) 18:765-7. doi: 10.1096/fj.03-0839fje

84. Lewkowicz N, Klink M, Mycko MP, Lewkowicz P. Neutrophil$\mathrm{CD} 4+\mathrm{CD} 25+\mathrm{T}$ regulatory cell interactions: a possible new mechanism of infectious tolerance. J Immunobiol. (2013) 218:455-64. doi: 10.1016/j.imbio.2012.05.029

85. McGonagle D, McDermott MF. A proposed classification of the immunological diseases. PLoS Med. (2006) 3:e297. doi: 10.1371/journal.pmed.0030297

86. Scott JR, Chin BY, Bilban MH, Otterbein LE. Restoring HOmeostasis: is heme oxygenase-1 ready for the clinic? Trends Pharmacol Sci. (2007) 28:2005. doi: 10.1016/j.tips.2007.03.006

87. Dutra FF, Bozza MT. Heme on innate immunity and inflammation. Front Pharmacol. (2014) 5:115. doi: 10.3389/fphar.2014.00115

88. Mateus V, Rocha J, Mota-Filipe H, Sepodes B, Pinto R. Hemin reduces inflammation associated with TNBS-induced colitis. Clin Exp Gastroenterol. (2018) 11:325-34. doi: 10.2147/CEG.S166197

89. Xiang Y, Liu G, Yang L, Zhong JL. UVA-induced protection of skin through the induction of heme oxygenase-1. Biosci Trends. (2011) 5:23944. doi: 10.5582/bst.2011.v5.6.239

90. Anand David AV, Arulmoli R, Parasuraman S. Overviews of biological importance of quercetin: a bioactive flavonoid. Pharmacogn Rev. (2016). 10:84-9. doi: 10.4103/0973-7847.194044

91. Mariani C, Braca A, Vitalini S, De Tommasi N, Visioli F, Fico G. Flavonoid characterization and in vitro antioxidant activity of Aconitum anthora L. (Ranunculaceae). Phytochemistry. (2008) 69:12206. doi: 10.1016/j.phytochem.2007.12.009

92. Lesjak M, Beara I, Simin N, Pintać D, Majkić T, Bekvalac K, et al. Antioxidant and anti-inflammatory activities of quercetin and its derivatives. J Func Foods. (2018) 40:68-75. doi: 10.1016/j.jff.2017.10.047

93. Saw CLL, Guo Y, Yang AY, Paredes-Gonzalez X, Ramirez C, Pung D, et al. The berry constituents quercetin, kaempferol, and pterostilbene synergistically attenuate reactive oxygen species: involvement of the Nrf2-ARE signaling pathway. Food Chem Toxicol. (2014) 72:303-11. doi: 10.1016/j.fct.2014.07.038

94. Yao P, Nussler A, Liu L, Hao L, Song F, Schirmeier A, et al. Quercetin protects human hepatocytes from ethanol-derived oxidative stress by inducing heme oxygenase-1 via the MAPK/Nrf2 pathways. J Hepatol. (2007) 47:25361. doi: 10.1016/j.jhep.2007.02.008

95. Lin H-C, Cheng T-H, Chen Y-C, Juan S-H. Mechanism of heme oxygenase1 gene induction by quercetin in rat aortic smooth muscle cells. Pharmacol. (2004) 71:107-12. doi: 10.1159/000076947

96. Sun GY, Chen Z, Jasmer KJ, Chuang DY, Gu Z, Hannink M, et al. Quercetin attenuates inflammatory responses in BV-2 microglial cells: role of MAPKs on the Nrf2 pathway and induction of heme oxygenase-1. PLoS ONE. (2015) 10:e0141509. doi: 10.1371/journal.pone.014 1509
97. Funes SC, Rios M, Escobar-Vera J, Kalergis AM. Implications of macrophage polarization in autoimmunity. Immunology. (2018) 154:18695. doi: 10.1111/imm.12910

98. Kim C-S, Choi H-S, Joe Y, Chung HT, Yu R. Induction of heme oxygenase1 with dietary quercetin reduces obesity-induced hepatic inflammation through macrophage phenotype switching. Nutr Res Pract. (2016) 10:6238. doi: $10.4162 /$ nrp.2016.10.6.623

99. Lu H, Wu L, Liu L, Ruan Q, Zhang X, Hong W, et al. Quercetin ameliorates kidney injury and fibrosis by modulating M1/M2 macrophage polarization. Biochem Pharmacol. (2018) 154:203-12. doi: 10.1016/j.bcp.2018.05.007

100. Yang Y, Zhang X, Xu M, Wu X, Zhao F, Zhao C. Quercetin attenuates collagen-induced arthritis by restoration of Th17/Treg balance and activation of heme oxygenase 1-mediated anti-inflammatory effect. Int Immunopharmacol. (2018) 54:153-62. doi: 10.1016/j.intimp.2017.11.013

101. Guazelli CF, Staurengo-Ferrari L, Zarpelon AC, Pinho-Ribeiro FA, Ruiz-Miyazawa KW, Vicentini FT, et al. Quercetin attenuates zymosan-induced arthritis in mice. Biomed Pharmacother. (2018) 102:175-84. doi: 10.1016/j.biopha.2018.03.057

102. Okamoto T. Safety of quercetin for clinical application. Int J Mol Med. (2005) 16:275-8. doi: 10.3892/ijmm.16.2.275

103. Harwood M, Danielewska-Nikiel B, Borzelleca JF, Flamm GW, Williams GM, Lines TC. A critical review of the data related to the safety of quercetin and lack of evidence of in vivo toxicity, including lack of genotoxic/carcinogenic properties. Food Chem Toxicol. (2007) 45:2179205. doi: 10.1016/j.fct.2007.05.015

104. Strimpakos AS, Sharma RA. Curcumin: preventive and therapeutic properties in laboratory studies and clinical trials. Antioxid Redox Signal. (2008) 10:511-46. doi: 10.1089/ars.2007.1769

105. Xie Z, Wu B, Shen G, Li X, Wu Q. Curcumin alleviates liver oxidative stress in type 1 diabetic rats. Mol Med Rep. (2018) 17:1038. doi: 10.3892/mmr.2017.7911

106. Peng X, Dai C, Liu Q, Li J, Qiu J. Curcumin attenuates on carbon tetrachloride-induced acute liver injury in mice via modulation of the Nrf2/HO-1 and TGF- $\beta 1 / \mathrm{Smad} 3$ pathway. Molecules. (2018) 23:215. doi: $10.3390 /$ molecules 23010215

107. Brück J, Holstein J, Glocova I, Seidel U, Geisel J, Kanno T, et al. Nutritional control of IL-23/Th17-mediated autoimmune disease through HO-1/STAT3 activation. Sci Rep. (2017) 7:44482. doi: 10.1038/srep44482

108. Yu Y, Shen Q, Lai Y, Park SY, Ou X, Lin D, et al. Anti-inflammatory effects of curcumin in microglial cells. Front Pharmacol. (2018) 9:386. doi: 10.3389/fphar.2018.00386

109. Yang X, Jiang H, Shi Y. Upregulation of heme oxygenase-1 expression by curcumin conferring protection from hydrogen peroxideinduced apoptosis in H9c2 cardiomyoblasts. Cell Biosci. (2017) 7:20. doi: 10.1186/s13578-017-0146-6

110. Damarla SR, Komma R, Bhatnagar U, Rajesh N, Mulla SMA. An evaluation of the genotoxicity and subchronic oral toxicity of synthetic curcumin. $J$ Toxicol. (2018) 2018:6872753. doi: 10.1155/2018/6872753

111. Cao J, Jia L, Zhou H-M, Liu Y, Zhong L-F. Mitochondrial and nuclear DNA damage induced by curcumin in human hepatoma G2 cells. Toxicol Sci. (2006) 91:476-83. doi: 10.1093/toxsci/kfj153

112. Anand P, Kunnumakkara AB, Newman RA, Aggarwal BB. Bioavailability of curcumin: problems and promises. Mol Pharm. (2007) 4:807-18. doi: 10.1021/mp700113r

113. Prasad S, Tyagi AK, Aggarwal BB. Recent developments in delivery, bioavailability, absorption and metabolism of curcumin: the golden pigment from golden spice. Cancer Res Treat. (2014) 46:2-18. doi: 10.4143/crt.2014.46.1.2

114. Birtić S, Dussort P, Pierre F-X, Bily AC, Roller M. Carnosic acid. Phytochemistry. (2015) 115:9-19. doi: 10.1016/j.phytochem.2014.12.026

115. Loussouarn M, Krieger-Liszkay A, Svilar L, Bily A, Birtić S, Havaux M. Carnosic acid and carnosol, two major antioxidants of rosemary, act through different mechanisms. Plant Physiol. (2017) 175:138194. doi: 10.1104/pp.17.01183

116. Arranz E, Jaime L, García-Risco MR, Fornari T, Reglero G, Santoyo S. Antiinflammatory activity of rosemary extracts obtained by supercritical carbon dioxide enriched in carnosic acid and carnosol. Int J Food Sci Technol. (2015) 50:674-81. doi: 10.1111/ijfs. 12656 
117. Martin D, Rojo AI, Salinas M, Diaz R, Gallardo G, Alam J, et al. Regulation of heme oxygenase-1 expression through the phosphatidylinositol 3kinase/Akt pathway and the Nrf2 transcription factor in response to the antioxidant phytochemical carnosol. J Biol Chem. (2004) 279:891929. doi: 10.1074/jbc.M309660200

118. Xiang Q, Wang Y, Wu W, Meng X, Qiao Y, Xu L, et al. Carnosic acid protects against ROS/RNS-induced protein damage and upregulates $\mathrm{HO}$ 1 expression in RAW264. 7 macrophages. J Func Foods. (2013) 5:3629. doi: 10.1016/j.jff.2012.11.007

119. Campbell NK, Fitzgerald HK, Malara A, Hambly R, Sweeney CM, Kirby B, et al. Naturally derived heme-oxygenase 1 inducers attenuate inflammatory responses in human dendritic cells and $\mathrm{T}$ cells: relevance for psoriasis treatment. Sci Rep. (2018) 8:10287. doi: 10.1038/s41598-018-28488-6

120. Campbell NK, Fitzgerald HK, Fletcher JM, Dunne A. Plant-derived polyphenols modulate human dendritic cell metabolism and immune function via AMPK-dependent induction of heme oxygenase-1. Front Immunol. (2019) 10:345. doi: 10.3389/fimmu.2019.00345

121. Foresti R, Bains SK, Pitchumony TS, de Castro Brás LE, Drago F, DuboisRandé J-L, et al. Small molecule activators of the Nrf2-HO-1 antioxidant axis modulate heme metabolism and inflammation in BV2 microglia cells. Pharmacol Res. (2013) 76:132-48. doi: 10.1016/j.phrs.2013.07.010

122. Feng X, Wu X, Wu Y, Zhao Z, Xiang C, Bai X, et al. Critical roles of tyrosyl-DNA phosphodiesterases in cell tolerance to carnosol-induced DNA damage. Cell Biol Int. (2020). doi: 10.1002/cbin.11357. [Epub ahead of print].

123. Arranz E, Santoyo S, Jaime L, Fornari T, Reglero G, Guri A, et al. Improved bioavailability of supercritical rosemary extract through encapsulation in different delivery systems after in vitro digestion. Food Dig Res Curr Opin. (2015) 6:30-7. doi: 10.1007/s13228-015-0040-9

124. Yeung AWK, Aggarwal BB, Orhan IE, Horbanczuk OK, Barreca D, Battino $\mathrm{M}$, et al. Resveratrol, a popular dietary supplement for human and animal health: quantitative research literature analysis-a review. Anim Sci Papers Rep. (2019) 37:103-18.

125. Berman AY, Motechin RA, Wiesenfeld MY, Holz MK. The therapeutic potential of resveratrol: a review of clinical trials. NPJ Precision Oncol. (2017) 1:35. doi: 10.1038/s41698-017-0038-6

126. Hui Y, Chengyong T, Cheng L, Haixia H, Yuanda Z, Weihua Y. Resveratrol attenuates the cytotoxicity induced by amyloid- $\beta$ 1-42 in PC12 cells by upregulating heme oxygenase-1 via the PI3K/Akt/Nrf2 pathway. Neurochem Res. (2018) 43:297-305. doi: 10.1007/s11064-017-2421-7

127. Chen C-Y, Jang J-H, Li M-H, Surh Y-J. Resveratrol upregulates heme oxygenase-1 expression via activation of NF-E2-related factor 2 in PC12 cells. Biochem Biophys Res Commun. (2005) 331:993-1000. doi: 10.1016/j.bbrc.2005.03.237

128. Iwasaki K, Ray PD, Huang B-W, Sakamoto K, Kobayashi T, Tsuji Y. Role of AMP-activated protein kinase in ferritin $\mathrm{H}$ gene expression by resveratrol in human T cells. Biochem. (2013) 52:5075-83. doi: 10.1021/bi400399f

129. Wung B-S, Hsu M-C, Wu C-C, Hsieh C-W. Piceatannol upregulates endothelial heme oxygenase-1 expression via novel protein kinase C and tyrosine kinase pathways. Pharmacol Res. (2006) 53:113-22. doi: 10.1016/j.phrs.2005.09.006

130. Adiabouah Achy-Brou CA, Billack B. A comparative assessment of the cytotoxicity and nitric oxide reducing ability of resveratrol, pterostilbene and piceatannol in transformed and normal mouse macrophages. Drug Chem Toxicol. (2017) 40:36-46. doi: 10.3109/01480545.2016.1169542

131. Walle T. Bioavailability of resveratrol. Ann N Y Acad Sci. (2011) 1215:915. doi: 10.1111/j.1749-6632.2010.05842.x

132. Santos AC, Pereira I, Pereira-Silva M, Ferreira L, Caldas M, ColladoGonzález M, et al. Nanotechnology-based formulations for resveratrol delivery: effects on resveratrol in vivo bioavailability and bioactivity. Colloids Surf B Biointerfaces. (2019) 180:127-40. doi: 10.1016/j.colsurfb.2019.04.030

133. Li D, Wang P, Luo Y, Zhao M, Chen F. Health benefits of anthocyanins and molecular mechanisms: update from recent decade. Crit Rev Food Sci Nutr. (2017) 57:1729-41. doi: 10.1080/10408398.2015.1030064

134. Hecht SS, Huang C, Stoner GD, Li J, Kenney PM, Sturla SJ, et al. Identification of cyanidin glycosides as constituents of freeze-dried black raspberries which inhibit anti-benzo [a] pyrene-7, 8-diol-9, 10-epoxide induced NFKB and AP-1 activity. Carcinogenesis. (2006) 27:1617-26. doi: 10.1093/carcin/ bgi366
135. Zhu Y, Ling W, Guo H, Song F, Ye Q, Zou T, et al. Anti-inflammatory effect of purified dietary anthocyanin in adults with hypercholesterolemia: a randomized controlled trial. Nutr Metab Cardiovasc Dis. (2013) 23:8439. doi: 10.1016/j.numecd.2012.06.005

136. Song Y, Huang L, Yu J. Effects of blueberry anthocyanins on retinal oxidative stress and inflammation in diabetes through $\mathrm{Nrf} 2 / \mathrm{HO}-1$ signaling. J Neuroimmunol. (2016) 301:1-6. doi: 10.1016/j.jneuroim.2016.11.001

137. Ali T, Kim T, Rehman SU, Khan MS, Amin FU, Khan M, et al. Natural dietary supplementation of anthocyanins via PI3K/Akt/Nrf2/HO1 pathways mitigate oxidative stress, neurodegeneration, and memory impairment in a mouse model of alzheimer's disease. Mol Neurobiol. (2018) 55:6076-93. doi: 10.1007/s12035-017-0798-6

138. Hwang YP, Choi JH, Yun HJ, Han EH, Kim HG, Kim JY, et al. Anthocyanins from purple sweet potato attenuate dimethylnitrosamineinduced liver injury in rats by inducing Nrf2-mediated antioxidant enzymes and reducing COX-2 and iNOS expression. Food Chem Toxicol. (2011) 49:93-9. doi: 10.1016/j.fct.2010.10.002

139. Min HK, Kim S-M, Baek S-Y, Woo J-W, Park J-S, Cho M-L, et al. Anthocyanin extracted from black soybean seed coats prevents autoimmune arthritis by suppressing the development of Th17 cells and synthesis of proinflammatory cytokines by such cells, via inhibition of NF-кB. PLoS ONE. (2015) 10:e0138201. doi: 10.1371/journal.pone.0138201

140. Wu S, He X, Wu X, Qin S, He J, Zhang S, et al. Inhibitory effects of blue honeysuckle (Lonicera caerulea L.) on adjuvant-induced arthritis in rats: crosstalk of anti-inflammatory and antioxidant effects. J Func Foods. (2015) 17:514-23. doi: 10.1016/j.jff.2015.06.007

141. Wang Y-P, Cheng M-L, Zhang B-F, Mu M, Zhou M-Y, Wu J, et al. Effect of blueberry on hepatic and immunological functions in mice. Hepatobil Pancreat Dis Int. (2010) 9:164-8.

142. Di Nunzio M, Valli V, Tomás-Cobos L, Tomás-Chisbert T, Murgui-Bosch $\mathrm{L}$, Danesi $\mathrm{F}$, et al. Is cytotoxicity a determinant of the different in vitro and in vivo effects of bioactives? BMC Complement Altern Med. (2017) 17:453. doi: 10.1186/s12906-017-1962-2

143. Fang J. Bioavailability of anthocyanins. Drug Metab Rev. (2014) 46:50820. doi: 10.3109/03602532.2014.978080

144. Manach C, Williamson G, Morand C, Scalbert A, Rémésy C. Bioavailability and bioefficacy of polyphenols in humans. I. Review of 97 bioavailability studies. Am J Clin Nutr. (2005) 81:230S-42S. doi: 10.1093/ajcn/81.1.230S

145. Atomssa T, Gholap A. Characterization and determination of catechins in green tea leaves using UV-visible spectrometer. J Eng Technol Res. (2015) 7:22-31.

146. Higdon JV, Frei B. Tea catechins and polyphenols: health effects, metabolism, and antioxidant functions. Crit Rev Food Sci Nutr. (2003) 43:89143. doi: 10.1080/10408690390826464

147. Xing L, Zhang H, Qi R, Tsao R, Mine Y. Recent advances in the understanding of the health benefits and molecular mechanisms associated with green tea polyphenols. J Agric Food Chem. (2019) 67:102943. doi: 10.1021/acs.jafc.8b06146

148. Saleh F, Raghupathy R, Asfar S, Oteifa M, Al-Saleh N. Analysis of the effect of the active compound of green tea (EGCG) on the proliferation of peripheral blood mononuclear cells. BMC complement Altern Med. (2014) 14:322. doi: 10.1186/1472-6882-14-322

149. Wu D, Wang J, Pae M, Meydani SN. Green tea EGCG, T cells, and T cell-mediated autoimmune diseases. Mol Aspects Med. (2012) 33:10718. doi: 10.1016/j.mam.2011.10.001

150. Kuo C-L, Chen T-S, Liou S-Y, Hsieh C-C. Immunomodulatory effects of EGCG fraction of green tea extract in innate and adaptive immunity via $\mathrm{T}$ regulatory cells in murine model. Immunopharmacol Immunotoxicol. (2014) 36:364-70. doi: 10.3109/08923973.2014.953637

151. Sahin K, Tuzcu M, Gencoglu H, Dogukan A, Timurkan M, Sahin N, et al. Epigallocatechin-3-gallate activates $\mathrm{Nrf} 2 / \mathrm{HO}-1$ signaling pathway in cisplatin-induced nephrotoxicity in rats. Life Sci. (2010) 87:2405. doi: 10.1016/j.lfs.2010.06.014

152. Peng A, Ye T, Rakheja D, Tu Y, Wang T, Du Y, et al. The green tea polyphenol (-)-epigallocatechin-3-gallate ameliorates experimental immune-mediated glomerulonephritis. Kidney Int. (2011) 80:601-11. doi: 10.1038/ki.2011.121

153. Kakuta Y, Okumi M, Isaka Y, Tsutahara K, Abe T, Yazawa K, et al. Epigallocatechin-3-gallate protects kidneys from ischemia reperfusion injury 
by HO-1 upregulation and inhibition of macrophage infiltration. Transpl Int. (2011) 24:514-22. doi: 10.1111/j.1432-2277.2011.01224.x

154. Kim Y, Lee J. Effect of (-)-epigallocatechin-3-gallate on antiinflammatory response via heme oxygenase-1 induction during adipocyte-macrophage interactions. Food Sci Biotechnol. (2016) 25:1767-73. doi: 10.1007/s10068-016-0269-2

155. Miao Y, Sun X, Gao G, Jia X, Wu H, Chen Y, et al. Evaluation of (-)-epigallocatechin-3-gallate (EGCG)-induced cytotoxicity on astrocytes: a potential mechanism of calcium overloadinginduced mitochondrial dysfunction. Toxicol in vitro. (2019) 61:104592. doi: 10.1016/j.tiv.2019.104592

156. Gan R-Y, Li H-B, Sui Z-Q, Corke H. Absorption, metabolism, anti-cancer effect and molecular targets of epigallocatechin gallate (EGCG): an updated review. Crit Rev Food Sci Nutr. (2018) 58:924-41. doi: 10.1080/10408398.2016.1231168

157. Ahmed RSI, Liu G, Renzetti A, Farshi P, Yang H, Soave C, et al. Biological and mechanistic characterization of novel prodrugs of green tea polyphenol epigallocatechin gallate analogs in human leiomyoma cell lines. J Cell Biochem. (2016) 117:2357-69. doi: 10.1002/jcb.25533

158. Liu B, Yan W. Lipophilization of EGCG and effects on antioxidant activities. Food Chem. (2019) 272:663-9. doi: 10.1016/j.foodchem.2018.08.086

159. Barbosa M, Lopes G, Andrade PB, Valentão P. Bioprospecting of brown seaweeds for biotechnological applications: phlorotannin actions in inflammation and allergy network. Trends Food Sci Technol. (2019) 86:15371. doi: $10.1016 /$ j.tifs.2019.02.037

160. Wijesinghe W, Ahn G, Lee W-W, Kang M-C, Kim E-A, Jeon Y-J. Anti-inflammatory activity of phlorotannin-rich fermented ecklonia cava processing by-product extract in lipopolysaccharidestimulated RAW 264.7 macrophages. J Appl Phycol. (2013) 25:1207-13. doi: 10.1007/s10811-012-9939-5

161. Yang Y-I, Woo J-H, Seo Y-J, Lee K-T, Lim Y, Choi J-H. Protective effect of brown alga phlorotannins against hyper-inflammatory responses in lipopolysaccharide-induced sepsis models. J Agric Food Chem. (2016) 64:570-8. doi: 10.1021/acs.jafc.5b04482

162. Kim S, Choi S-I, Kim G-H, Imm J-Y. Anti-inflammatory effect of Ecklonia cava extract on Porphyromonas gingivalis lipopolysaccharidestimulated macrophages and a periodontitis rat model. Nutrients. (2019) 11:1143. doi: $10.3390 /$ nu11051143

163. Lee M-S, Kwon M-S, Choi J-W, Shin T, No HK, Choi J-S, et al. Antiinflammatory activities of an ethanol extract of Ecklonia stolonifera in lipopolysaccharide-stimulated RAW 264.7 murine macrophage cells. J Agric Food Chem. (2012) 60:9120-9. doi: 10.1021/jf3022018

164. Sanjeewa KKA, Fernando IP, Kim H, Jayawardena TU, Ryu B, Yang H-W, et al. Dieckol: an algal polyphenol attenuates urban fine dustinduced inflammation in RAW 264.7 cells via the activation of antiinflammatory and antioxidant signaling pathways. J Appl Phycol. (2019). doi: 10.1007/s10811-019-01964-w

165. Yayeh T, Im EJ, Kwon T-H, Roh S-S, Kim S, Kim JH, et al. Hemeoxygenase 1 partly mediates the anti-inflammatory effect of dieckol in lipopolysaccharide stimulated murine macrophages. Int Immunopharmacol. (2014) 22:518. doi: 10.1016/j.intimp.2014.06.009

166. Nagayama K, Iwamura Y, Shibata T, Hirayama I, Nakamura T. Bactericidal activity of phlorotannins from the brown alga ecklonia kurome. Antimicrobial Chemother. (2002) 50:889-93. doi: 10.1093/jac/dkf222

167. Corona G, Ji Y, Anegboonlap P, Hotchkiss S, Gill C, Yaqoob P, et al. Gastrointestinal modifications and bioavailability of brown seaweed phlorotannins and effects on inflammatory markers. Br J Nutr. (2016) 115:1240-53. doi: 10.1017/S0007114516000210

168. Kim D, Shin E, Kim Y, Lee B, Jun JG, Park J, et al. Suppression of inflammatory responses by celastrol, a quinone methide triterpenoid isolated from Celastrus regelii. Eur J Clin Invest. (2009) 39:81927. doi: 10.1111/j.1365-2362.2009.02186.x

169. Venkatesha SH, Moudgil KD. Celastrol and its role in controlling chronic diseases. Adv Exp Med Biol. (2016) 928:26789. doi: 10.1007/978-3-319-41334-1_12

170. Luo D, Guo Y, Cheng Y, Zhao J, Wang Y, Rong J. Natural product celastrol suppressed macrophage M1 polarization against inflammation in diet-induced obese mice via regulating $\mathrm{Nrf} 2 / \mathrm{HO}-1$, MAP kinase and NF-кB pathways. Aging. (2017) 9:2069-82. doi: 10.18632/aging.10 1302

171. Wei H-J, Pareek TK, Liu Q, Letterio JJ. A unique tolerizing dendritic cell phenotype induced by the synthetic triterpenoid CDDO-DFPA (RTA-408) is protective against EAE. Sci Rep. (2017) 7:9886. doi: 10.1038/s41598-017-06907-4

172. Cascão R, Carvalho T, Goncalves J, Moita L, Fonseca J. AB0096 Efficacy and Safety of Oral Administration of Pure Celastrol in Aia Rats. London, UK: BMJ Publishing Group Ltd (2017). doi: 10.1136/annrheumdis-2017-eular.2868

173. Konieczny J, Jantas D, Lenda T, Domin H, Czarnecka A, Kuter K, et al. Lack of neuroprotective effect of celastrol under conditions of proteasome inhibition by lactacystin in in vitro and in vivo studies: implications for Parkinson's disease. Neurotoxicity Res. (2014) 26:25573. doi: 10.1007/s12640-014-9477-9

174. Bai J-P, Shi Y-L, Fang X, Shi Q-X. Effects of demethylzeylasteral and celastrol on spermatogenic cell $\mathrm{Ca} 2+$ channels and progesteroneinduced sperm acrosome reaction. Eur J Pharmacol. (2003) 464:915. doi: 10.1016/S0014-2999(03)01351-7

175. Cascão R, Fonseca JE, Moita LF. Celastrol: a spectrum of treatment opportunities in chronic diseases. Front Med. (2017) 4:69. doi: 10.3389/fmed.2017.00069

176. Zhang J, Li C-Y, Xu M-j, Wu T, Chu J-H, Liu S-J, et al. Oral bioavailability and gender-related pharmacokinetics of celastrol following administration of pure celastrol and its related tablets in rats. J Ethnopharmacol. (2012) 144:195-200. doi: 10.1016/j.jep.2012.09.005

177. Hou W, Liu B, Xu H. Celastrol: progresses in structure-modifications, structure-activity relationships, pharmacology and toxicology. Eur J Med Chem. (2020) 189:112081. doi: 10.1016/j.ejmech.2020.112081

178. Castaldo S, Capasso F. Propolis, an old remedy used in modern medicine. $J$ Fitoterapia. (2002) 73:S1-S6. doi: 10.1016/S0367-326X(02)00185-5

179. Armutcu F, Akyol S, Ustunsoy S, Turan FF. Therapeutic potential of caffeic acid phenethyl ester and its anti-inflammatory and immunomodulatory effects. J Exp Ther Med. (2015) 9:1582-8. doi: 10.3892/etm.2015.2346

180. Wang L-C, Lin Y-L, Liang Y-C, Yang Y-H, Lee J-H, Yu H-H, et al. The effect of caffeic acid phenethyl ester on the functions of human monocyte-derived dendritic cells. BMC Immunol. (2009) 10:39. doi: 10.1186/1471-2172-10-39

181. Ansorge S, Reinhold D, Lendeckel U. Propolis and some of its constituents down-regulate DNA synthesis and inflammatory cytokine production but induce TGF- $\beta 1$ production of human immune cells. Z Naturforsch C. (2003) 58:580-9. doi: 10.1515/znc-2003-7-823

182. Stähli A, Maheen CU, Strauss FJ, Eick S, Sculean A, Gruber R. Caffeic acid phenethyl ester protects against oxidative stress and dampens inflammation via heme oxygenase 1. Int J Oral Sci. (2019) 11:6. doi: 10.1038/s41368-018-0039-5

183. Natarajan K, Singh S, Burke TR, Grunberger D, Aggarwal BB. Caffeic acid phenethyl ester is a potent and specific inhibitor of activation of nuclear transcription factor NF-kappa B. Proc Natl Acad Sci USA. (1996) 93:90905. doi: 10.1073/pnas.93.17.9090

184. Cheng Y, Yang C, Luo D, Li X, Le XC, Rong J. N-propargyl caffeamide skews macrophages towards a resolving M2-like phenotype against myocardial ischemic injury via activating Nrf2/HO-1 pathway and inhibiting NFкB pathway. Cell Physiol Biochem. (2018) 47:2544-57. doi: 10.1159/0004 91651

185. Tsai C-F, Kuo Y-H, Yeh W-L, Wu CY-J, Lin H-Y, Lai S-W, et al. Regulatory effects of caffeic acid phenethyl ester on neuroinflammation in microglial cells. Int J Mol Sci. (2015) 16:5572-89. doi: 10.3390/ijms16035572

186. Pittala V, Vanella L, Salerno L, Di Giacomo C, Acquaviva R, Raffaele $\mathrm{M}$, et al. Novel caffeic acid phenethyl ester (Cape) analogues as inducers of heme oxygenase-1. Curr Pharm Des. (2017) 23:265764. doi: 10.2174/1381612823666170210151411

187. Wang X, Stavchansky S, Kerwin SM, Bowman PD. Structure-activity relationships in the cytoprotective effect of caffeic acid phenethyl ester (CAPE) and fluorinated derivatives: effects on heme oxygenase1 induction and antioxidant activities. Eur J Pharmacol. (2010) 635:1622. doi: 10.1016/j.ejphar.2010.02.034

188. Moon K-O, Park S, Joo M, Ha K-T, Baek N-I, Park C-S, et al. Glycosylation enhances the physicochemical properties of caffeic acid phenethyl ester. $J$ Microbiol Biotechnol. (2017) 27:1916-24. doi: 10.4014/jmb.1706.06017 
189. Burdock GA. Review of the biological properties and toxicity of bee propolis (propolis). Food Chem Toxicol. (1998) 36:34763. doi: 10.1016/S0278-6915(97)00145-2

190. Mohammadzadeh S, Shariatpanahi M, Hamedi M, Ahmadkhaniha R, Samadi N, Ostad SN. Chemical composition, oral toxicity and antimicrobial activity of Iranian propolis. Food Chem. (2007) 103:1097-103. doi: 10.1016/j.foodchem.2006.10.006

191. Asnin L, Park S. Isolation and analysis of bioactive compounds in capsicum peppers. Crit Rev Food Sci Nutr. (2015) 55:25489. doi: 10.1080/10408398.2011.652316

192. Kim C-S, Kawada T, Kim B-S, Han I-S, Choe S-Y, Kurata T, et al. Capsaicin exhibits anti-inflammatory property by inhibiting IkB-a degradation in LPS-stimulated peritoneal macrophages. Cell Signal. (2003) 15:299306. doi: 10.1016/S0898-6568(02)00086-4

193. Ghiasi Z, Esmaeli F, Aghajani M, Ghazi-Khansari M, Faramarzi MA, Amani A. Enhancing analgesic and anti-inflammatory effects of capsaicin when loaded into olive oil nanoemulsion: an in vivo study. Int J Pharm. (2019) 559:341-7. doi: 10.1016/j.ijpharm.2019.01.043

194. Pallavi P, Pretze M, Caballero J, Li Y, Hofmann BrB, Stamellou E, et al. Analyses of synthetic N-Acyl dopamine derivatives revealing different structural requirements for their anti-inflammatory and transient-receptor-potential-channel-of-the-vanilloid-receptor-subfamilysubtype-1 (TRPV1)-activating properties. J Med Chem. (2018) 61:3126-37. doi: 10.1021/acs.jmedchem.8b00156

195. Joung E-J, Li M-H, Lee HG, Somparn N, Jung YS, Na H-K, et al. Capsaicin induces heme oxygenase-1 expression in HepG2 cells via activation of PI3KNrf2 signaling: NAD (P) H: quinone oxidoreductase as a potential target. Antioxid Redox Signal. (2007) 9:2087-98. doi: 10.1089/ars.2007.1827

196. Shimeda Y, Hirotani Y, Akimoto Y, Shindou K, Ijiri Y, Nishihori T, et al. Protective effects of capsaicin against cisplatin-induced nephrotoxicity in rats. Biol Pharm Bull. (2005) 28:1635-8. doi: 10.1248/bpb.28.1635

197. Jung S-H, Kim H-J, Oh G-S, Shen A, Lee S, Choe S-K, et al. Capsaicin ameliorates cisplatin-induced renal injury through induction of heme oxygenase-1. Mol Cells. (2014) 37:234-40. doi: 10.14348/molcells.2014.2322

198. Kim Y, Lee J. Anti-inflammatory activity of capsaicin and dihydrocapsaicin through heme oxygenase-1 induction in raw264. 7 macrophages. J Food Biochem. (2014) 38:381-7. doi: 10.1111/jfbc.12064

199. Rollyson WD, Stover CA, Brown KC, Perry HE, Stevenson CD, McNees CA, et al. Bioavailability of capsaicin and its implications for drug delivery. $J$ Control Release. (2014) 196:96-105. doi: 10.1016/j.jconrel.2014.09.027

200. Surh Y-J, Sup Lee S. Capsaicin, a double-edged sword: toxicity, metabolism, and chemopreventive potential. Life Sci. (1995) 56:1845-55. doi: 10.1016/0024-3205(95)00159-4

201. Chang A, Quick J. Capsaicin. Treasure Island, FL: StatPearls Publishing (2019).

202. Petropoulos S, Di Gioia F, Ntatsi G. Vegetable organosulfur compounds and their health promoting effects. Curr Pharm Des. (2017) 23:285075. doi: 10.2174/1381612823666170111100531

203. Arreola R, Quintero-Fabián S, López-Roa RI, Flores-Gutiérrez EO, Reyes-Grajeda JP, Carrera-Quintanar L, et al. Immunomodulation and anti-inflammatory effects of garlic compounds. J Immunol Res. (2015) 2015:401630. doi: 10.1155/2015/401630

204. Trio PZ, You S, He X, He J, Sakao K, Hou D-X. Chemopreventive functions and molecular mechanisms of garlic organosulfur compounds. Food Func. (2014) 5:833-44. doi: 10.1039/c3fo60479a

205. Jeong Y, Ryu J, Shin J-H, Kang M, Kang J, Han J, et al. Comparison of antioxidant and anti-inflammatory effects between fresh and aged black garlic extracts. Molecules. (2016) 21:430. doi: 10.3390/molecules21040430

206. Chen C, Pung D, Leong V, Hebbar V, Shen G, Nair S, et al. Induction of detoxifying enzymes by garlic organosulfur compounds through transcription factor Nrf2: effect of chemical structure and stress signals. Free Radical Biol Med. (2004) 37:1578-90. doi: 10.1016/j.freeradbiomed.2004.07.021

207. Shin I-S, Hong J, Jeon C-M, Shin N-R, Kwon O-K, Kim H$S$, et al. Diallyl-disulfide, an organosulfur compound of garlic, attenuates airway inflammation via activation of the Nrf-2/HO1 pathway and NF-kappaB suppression. Food Chem Toxicol. (2013) 62:506-13. doi: 10.1016/j.fct.2013.09.012
208. Baluchnejadmojarad T, Kiasalari Z, Afshin-Majd S, Ghasemi Z, Roghani M. S-allyl cysteine ameliorates cognitive deficits in streptozotocin-diabetic rats via suppression of oxidative stress, inflammation, and acetylcholinesterase. Eur J Pharmacol. (2017) 794:69-76. doi: 10.1016/j.ejphar.2016. 11.033

209. Park H-J, Jeon BT, Kim HC, Roh GS, Shin J-H, Sung N-J, et al. Aged red garlic extract reduces lipopolysaccharide-induced nitric oxide production in RAW 264.7 macrophages and acute pulmonary inflammation through haeme oxygenase-1 induction. Acta Physiol. (2012) 205:6170. doi: $10.1111 /$ j.1748-1716.2012.02425.x

210. Mellado-García P, Maisanaba S, Puerto M, Prieto AI, Marcos R, Pichardo S, et al. In vitro toxicological assessment of an organosulfur compound from allium extract: cytotoxicity, mutagenicity and genotoxicity studies. Food Chem Toxicol. (2017) 99:231-40. doi: 10.1016/j.fct.2016.12.007

211. Mellado-García P, Puerto M, Pichardo S, Llana-Ruiz-Cabello M, Moyano $\mathrm{R}$, Blanco A, et al. Toxicological evaluation of an allium-based commercial product in a 90-day feeding study in sprague-dawley rats. Food Chem Toxicol. (2016) 90:18-29. doi: 10.1016/j.fct.2016.01.019

212. Putnik P, Gabrić D, Roohinejad S, Barba FJ, Granato D, Lorenzo JM, et al. Bioavailability and food production of organosulfur compounds from edible allium species. In: Barba FJ, Saraiva JMA, Cravotto G, Lorenzo JM, editors. Innovative Thermal and Non-Thermal Processing, Bioaccessibility and Bioavailability of Nutrients and Bioactive Compounds. Cambridge: Woodhead Publishing (2019). p. 293-308. doi: 10.1016/B978-0-12-814174-8.00010-X

213. Nakamura Y. Chemoprevention by isothiocyanates: molecular basis of apoptosis induction. Forum Nutr. (2009) 61:170-81. doi: 10.1159/000212749

214. Galuppo M, Giacoppo S, De Nicola GR, Iori R, Navarra M, Lombardo GE, et al. Antiinflammatory activity of glucomoringin isothiocyanate in a mouse model of experimental autoimmune encephalomyelitis. Fitoterapia. (2014) 95:160-74. doi: 10.1016/j.fitote.2014.03.018

215. Giacoppo S, Rajan TS, Iori R, Rollin P, Bramanti P, Mazzon E. The $\alpha$-cyclodextrin complex of the moringa isothiocyanate suppresses lipopolysaccharide-induced inflammation in RAW 264.7 macrophage cells through Akt and p38 inhibition. Inflamm Res. (2017) 66:487503. doi: 10.1007/s00011-017-1033-7

216. Gründemann C, Huber R. Chemoprevention with isothiocyanatesfrom bench to bedside. Cancer Lett. (2018) 414:2633. doi: 10.1016/j.canlet.2017.10.033

217. Bao B, Zhang MQ, Chen ZY, Wu XB, Xia ZB, Chai JY, et al. Sulforaphane prevents PC12 cells from oxidative damage via the Nrf2 pathway. Mol Med Rep. (2019) 19:4890-6. doi: 10.3892/mmr.2019.10148

218. Lv D, Zhou Q, Xia Y, You X, Zhao Z, Li Y, et al. The association between oxidative stress alleviation via sulforaphane-induced Nrf2HO-1/NQO-1 signaling pathway activation and chronic renal allograft dysfunction improvement. Kidney Blood Pressure Res. (2018) 43:191205. doi: 10.1159/000487501

219. Liang J, Jahraus B, Balta E, Huebner K, Blank N, Niesler B, et al. Sulforaphane inhibits inflammatory responses of primary human T-cells by increasing ROS and depleting glutathione. Front Immunol. (2018) 9:2584. doi: 10.3389/fimmu.2018.02584

220. Haodang L, Lianmei Q, Ranhui L, Liesong C, Jun H, Yihua Z, et al. HO1 mediates the anti-inflammatory actions of Sulforaphane in monocytes stimulated with a mycoplasmal lipopeptide. Chem Biol Interact. (2019) 306:10-8. doi: 10.1016/j.cbi.2019.04.007

221. Ruhee RT, Ma S, Suzuki K. Sulforaphane protects cells against lipopolysaccharide-stimulated inflammation in murine macrophages. Antioxidants. (2019) 8:577. doi: 10.3390/antiox8120577

222. Geisel J, Brück J, Glocova I, Dengler K, Sinnberg T, Rothfuss O, et al. Sulforaphane protects from $\mathrm{T}$ cell-mediated autoimmune disease by inhibition of IL-23 and IL-12 in dendritic cells. Immunol. (2014) 192:35309. doi: 10.4049/jimmunol.1300556

223. Oliviero T, Lamers S, Capuano E, Dekker M, Verkerk R. Bioavailability of isothiocyanates from broccoli sprouts in protein, lipid, and fiber gels. Mol Nutr Food Res. (2018) 62:1700837. doi: 10.1002/mnfr.201700837

224. Baenas N, Suárez-Martínez C, García-Viguera C, Moreno DA. Bioavailability and new biomarkers of cruciferous sprouts consumption. Food Res Int. (2017) 100:497-503. doi: 10.1016/j.foodres.2017.07.049 
225. Wu S, Gao Q, Zhao P, Gao Y, Xi Y, Wang X, et al. Sulforaphane produces antidepressant-and anxiolytic-like effects in adult mice. Behav Brain Res. (2016) 301:55-62. doi: 10.1016/j.bbr.2015.12.030

226. Socała K, Nieoczym D, Kowalczuk-Vasilev E, Wyska E, Wlaz P. Increased seizure susceptibility and other toxicity symptoms following acute sulforaphane treatment in mice. Toxicol Appl Pharmacol. (2017) 326:4353. doi: 10.1016/j.taap.2017.04.010

227. Li B-Z, Guo B, Zhang H-Y, Liu J, Tao S-S, Pan H-F, et al. Therapeutic potential of HO-1 in autoimmune diseases. Inflammation. (2014) 37:177988. doi: 10.1007/s10753-014-9908-z

228. Shibahara S. The heme oxygenase dilemma in cellular homeostasis: new insights for the feedback regulation of heme catabolism. Tohoku J Exp Med. (2003) 200:167-86. doi: 10.1620/tjem.200.167

229. Córdova EJ, Martínez-Hernández A, Ramírez-Bello J, Velázquez-Cruz R, Centeno F, Baca V, et al. HMOX1 promoter (GT)n polymorphim is associated with childhood-onset systemic lupus erythematosus but not with juvenile rheumatoid arthritis in a Mexican population. Clin Exp Rheumatol. (2012) 30:297-301.

230. Rueda B, Oliver J, Robledo G, López-Nevot MA, Balsa A, Pascual-Salcedo D, et al. HO-1 promoter polymorphism associated with rheumatoid arthritis. Arthritis Rheum. (2007) 56:3953-8. doi: 10.1002/art.23048

231. Ju S, Ge Y, Li P, Tian X, Wang H, Zheng X, et al. Dietary quercetin ameliorates experimental colitis in mouse by remodeling the function of colonic macrophages via a heme oxygenase-1-dependent pathway. Cell Cycle. (2018) 17:53-63. doi: 10.1080/15384101.2017.1387701

232. Aziz MTA, El-Asmar MF, El-Ibrashy IN, Rezq AM, Al-Malki AL, Wassef MA, et al. Effect of novel water soluble curcumin derivative on experimental type-1 diabetes mellitus (short term study). Diabetol Metab Synd. (2012) 4:30. doi: 10.1186/1758-5996-4-30

233. Soetikno V, Sari FR, Lakshmanan AP, Arumugam S, Harima M, Suzuki K, et al. Curcumin alleviates oxidative stress, inflammation, and renal fibrosis in remnant kidney through the $\mathrm{N}$ rf2-keap1 pathway. Mol Nutr Food Res. (2013) 57:1649-59. doi: 10.1002/mnfr.201200540

234. Zhao Y, Song W, Wang Z, Wang Z, Jin X, Xu J, et al. Resveratrol attenuates testicular apoptosis in type 1 diabetic mice: role of Akt-mediated Nrf2 activation and p62-dependent Keap1 degradation. Redox Biol. (2018) 14:609-17. doi: 10.1016/j.redox.2017.11.007

235. Hammad AS, Ahmed A-SF, Heeba GH, Taye AA. Resveratrol protects against early cardiomyopathic changes-induced by Type-1 diabetes through a heme-oxygenase-1 dependent mechanism. J Adv Biomed Pharm Sci. (2019) 2:12-8. doi: $10.21608 /$ jabps.2018.5175.1022

236. Wei Y, Jia J, Jin X, Tong W, Tian H. Resveratrol ameliorates inflammatory damage and protects against osteoarthritis in a rat model of osteoarthritis. Mol Med Rep. (2018) 17:1493-8. doi: 10.3892/mmr.2017.8036

237. Mazzon E, Muià C, Paola RD, Genovese T, Menegazzi M, De Sarro A, et al. Green tea polyphenol extract attenuates colon injury induced by experimental colitis. Free Radical Res. (2005) 39:1017-25. doi: 10.1080/10715760500197177

238. Sorrenti V, Raffaele M, Vanella L, Acquaviva R, Salerno L, Pittalà V, et al. Protective effects of caffeic acid phenethyl ester (CAPE) and novel cape analogue as inducers of heme oxygenase-1 in streptozotocin-induced type 1 diabetic rats. Int J Mol Sci. (2019) 20:2441. doi: 10.3390/ijms20 102441

239. Yu L, Li S, Tang $\mathrm{X}, \mathrm{Li} \mathrm{Z}$, Zhang J, Xue $\mathrm{X}$, et al. Diallyl trisulfide ameliorates myocardial ischemia-reperfusion injury by reducing oxidative stress and endoplasmic reticulum stress-mediated apoptosis in type 1 diabetic rats: role of SIRT1 activation. Apoptosis. (2017) 22:94254. doi: 10.1007/s10495-017-1378-y

240. Kim Y, Wu AG, Jaja-Chimedza A, Graf BL, Waterman C, Verzi MP, et al. Isothiocyanate-enriched moringa seed extract alleviates ulcerative colitis symptoms in mice. PLoS ONE. (2017) 12:e0184709. doi: 10.1371/journal.pone.0184709

241. Lassmann H, Bradl M. Multiple sclerosis: experimental models and reality. Acta Neuropathol. (2017) 133:223-44. doi: 10.1007/s00401-016-1631-4

242. Fagone P, Patti F, Mangano K, Mammana S, Coco M, Touil-Boukoffa C, et al. Heme oxygenase-1 expression in peripheral blood mononuclear cells correlates with disease activity in multiple sclerosis. J Neuroimmunol. (2013) 261:82-6. doi: 10.1016/j.jneuroim.2013.04.013
243. Fagone P, Mangano K, Coco M, Perciavalle V, Garotta G, Romao C, et al. Therapeutic potential of carbon monoxide in multiple sclerosis. Clin Exp Immunol. (2012) 167:179-87. doi: 10.1111/j.1365-2249.2011.04491.X

244. Ghoreschi K, Brück J, Kellerer C, Deng C, Peng H, Rothfuss O, et al. Fumarates improve psoriasis and multiple sclerosis by inducing type II dendritic cells. J Exp Med. (2011) 208:2291-303. doi: 10.1084/jem.20100977

245. Glatigny S, Bettelli E. Experimental autoimmune encephalomyelitis (EAE) as animal models of multiple sclerosis (MS). Cold Spring Harb Perspect Med. (2018) 8:a028977. doi: 10.1101/cshperspect.a028977

246. Chora ÂA, Fontoura P, Cunha A, Pais TF, Cardoso S, Ho PP, et al. Heme oxygenase -1 and carbon monoxide suppress autoimmune neuroinflammation. J Clin Invest. (2007) 117:438-47. doi: 10.1172/JCI28844

247. Ilhan A, Akyol O, Gurel A, Armutcu F, Iraz M, Oztas E. Protective effects of caffeic acid phenethyl ester against experimental allergic encephalomyelitisinduced oxidative stress in rats. Free Radical Biol Med. (2004) 37:38694. doi: 10.1016/j.freeradbiomed.2004.04.022

248. Lindbladh I, Svärd AA, Lernmark Å. Autoimmune (Type 1) Diabetes. The Autoimmune Diseases. San Diego, CA: Elsevier (2020). p. 769-87. doi: 10.1016/B978-0-12-812102-3.00041-5

249. Pogu J, Tzima S, Kollias G, Anegon I, Blancou P, Simon T. Genetic restoration of heme oxygenase-1 expression protects from type 1 diabetes in NOD mice. Int J Mol Sci. (2019) 20:1676. doi: 10.3390/ijms20071676

250. Husseini M, Wang G-S, Patrick C, Crookshank JA, MacFarlane AJ, Noel JA, et al. Heme oxygenase-1 induction prevents autoimmune diabetes in association with pancreatic recruitment of M2-like macrophages, mesenchymal cells, and fibrocytes. Endocrinology. (2015) 156:393749. doi: 10.1210/en.2015-1304

251. Jeremic JN, Jakovljevic VL, Zivkovic VI, Srejovic IM, Bradic JV, Bolevich $\mathrm{S}$, et al. The cardioprotective effects of diallyl trisulfide on diabetic rats with ex vivo induced ischemia/reperfusion injury. Mol Cell Biochem. (2019) 460:151-64. doi: 10.1007/s11010-019-03577-w

252. Gao S, Yang Z, Shi R, Xu D, Li H, Xia Z, et al. Diabetes blocks the cardioprotective effects of sevoflurane postconditioning by impairing Nrf2/Brg1/HO-1 signaling. Eur J Pharmacol. (2016) 779:111-21. doi: 10.1016/j.ejphar.2016.03.018

253. Catrina AI, Svensson CI, Malmström V, Schett G, Klareskog L. Mechanisms leading from systemic autoimmunity to jointspecific disease in rheumatoid arthritis. Nat Rev Rheumatol. (2017) 13:79-86. doi: 10.1038/nrrheum.2016.200

254. Kitamura A, Nishida K, Komiyama T, Doi H, Kadota Y, Yoshida A, et al. Increased level of heme oxygenase-1 in rheumatoid arthritis synovial fluid. Modern Rheumatol. (2011) 21:150-7. doi: 10.3109/s10165-010-0372-9

255. Kirino Y, Takeno M, Murakami S, Kobayashi M, Kobayashi H, Miura K, et al. Tumor necrosis factor $\alpha$ acceleration of inflammatory responses by downregulating heme oxygenase 1 in human peripheral monocytes. Arthritis Rheum. (2007) 56:464-75. doi: 10.1002/art.22370

256. Devesa I, Ferrándiz ML, Terencio MC, Joosten LA, van den Berg WB, Alcaraz MJ. Influence of heme oxygenase 1 modulation on the progression of murine collagen-induced arthritis. Arthritis Rheum. (2005) 52:32308. doi: 10.1002/art.21356

257. Devesa I, Ferrándiz ML, Guillén I, Cerdá JM, Alcaraz MJ. Potential role of heme oxygenase-1 in the progression of rat adjuvant arthritis. Lab Invest. (2005) 85:34-44. doi: 10.1038/labinvest.3700205

258. Morel L. Immunometabolism in systemic lupus erythematosus. Nat Rev Rheumatol. (2017) 13:280-90. doi: 10.1038/nrrheum.2017.43

259. Touma Z, Gladman DD. Current and future therapies for SLE: obstacles and recommendations for the development of novel treatments. Lupus Sci Med. (2017) 4:239. doi: 10.1136/lupus-2017-000239

260. Mackern-Oberti JP, Vega F, Llanos C, Bueno SM, Kalergis AM. Targeting dendritic cell function during systemic autoimmunity to restore tolerance. Int J Mol Sci. (2014) 15:16381-417. doi: 10.3390/ijms150916381

261. Mackern-Oberti JP, Llanos C, Carreño LJ, Riquelme SA, Jacobelli SH, Anegon I, et al. Carbon monoxide exposure improves immune function in lupusprone mice. Immunology. (2013) 140:123-32. doi: 10.1111/imm.12124

262. Funes SC, Ríos M, Gómez-Santander F, Fernández-Fierro A, AltamiranoLagos MJ, Rivera-Perez D, et al. Tolerogenic dendritic cell transfer ameliorates systemic lupus erythematosus in mice. Immunology. (2019) 158:322-39. doi: $10.1111 /$ imm.13119 
263. Herrada AA, Llanos C, Mackern-Oberti JP, Carreño LJ, Henriquez C, Gómez RS, et al. Haem oxygenase 1 expression is altered in monocytes from patients with systemic lupus erythematosus. Immunology. (2012) 136:41424. doi: 10.1111/j.1365-2567.2012.03598.x

264. Aparicio-Soto M, Sánchez-Hidalgo M, Cárdeno A, Rosillo MÁ, SánchezFidalgo S, Utrilla J, et al. Dietary extra virgin olive oil attenuates kidney injury in pristane-induced SLE model via activation of HO-1/Nrf-2 antioxidant pathway and suppression of JAK/STAT, NF-KB and MAPK activation. J Nutr Biochem. (2016) 27:278-88. doi: 10.1016/j.jnutbio.2015.09.017

265. Paul G, Bataille F, Obermeier F, Bock J, Klebl F, Strauch U, et al. Analysis of intestinal haem-oxygenase-1 (HO-1) in clinical and experimental colitis. Clin Exp Immunol. (2005) 140:547-55. doi: 10.1111/j.1365-2249.2005.02775.x

266. Shen N-Y, Bi J-B, Zhang J-Y, Zhang S-M, Gu J-X, Qu K, et al. Hydrogen-rich water protects against inflammatory bowel disease in mice by inhibiting endoplasmic reticulum stress and promoting heme oxygenase-1 expression. World J Gastroenterol. (2017) 23:1375-86. doi: 10.3748/wjg.v23.i8. 1375

267. Wang N, Wang G, Hao J, Ma J, Wang Y, Jiang X, et al. Curcumin ameliorates hydrogen peroxide-induced epithelial barrier disruption by upregulating heme oxygenase-1 expression in human intestinal epithelial cells. Dig Dis Sci. (2012) 57:1792-801. doi: 10.1007/s10620-012-2 094-7

268. Serra D, Almeida LM, Dinis TC. Anti-inflammatory protection afforded by cyanidin-3-glucoside and resveratrol in human intestinal cells via Nrf2 and PPAR- $\gamma$ : comparison with 5-aminosalicylic acid. Chem Biol Interact. (2016) 260:102-9. doi: 10.1016/j.cbi.2016.11.003

Conflict of Interest: The authors declare that the research was conducted in the absence of any commercial or financial relationships that could be construed as a potential conflict of interest.

Copyright (๑) 2020 Funes, Rios, Fernández-Fierro, Covián, Bueno, Riedel, MackernOberti and Kalergis. This is an open-access article distributed under the terms of the Creative Commons Attribution License (CC BY). The use, distribution or reproduction in other forums is permitted, provided the original author(s) and the copyright owner(s) are credited and that the original publication in this journal is cited, in accordance with accepted academic practice. No use, distribution or reproduction is permitted which does not comply with these terms. 